Supplementary Information for

\title{
A set of organelle-localizable reactive molecules for mitochondrial chemical proteomics in living cells and brain tissues
}

Yuki Yasueda, ${ }^{1}$ Tomonori Tamura, ${ }^{1}$ Alma Fujisawa, ${ }^{1}$ Keiko Kuwata, ${ }^{2}$ Shinya Tsukiji, ${ }^{3}$

Shigeki Kiyonaka ${ }^{1}$ and Itaru Hamachi ${ }^{1,4}$

${ }^{1}$ Department of Synthetic Chemistry and Biological Chemistry, Graduate School of Engineering, Kyoto University, Katsura, Nishikyo-ku, Kyoto 615-8510, JAPAN

${ }^{2}$ Institute of Transformative Bio-Molecules (ITbM), Nagoya University, Chikusa, Nagoya 464-8602, JAPAN

${ }^{3}$ Frontier Research Institute for Materials Science (FRIMS), Department of Life Science and Applied Chemistry, Department of Nanopharmaceutical Sciences, Nagoya Institute of Technology, Gokiso-cho, Showa-ku, Nagoya 466-8555, Japan

${ }^{4}$ CREST (Core Research for Evolutional Science and Technology, JST), Sanbancho, Chiyodaku, Tokyo, 102-0075, JAPAN 
(a)

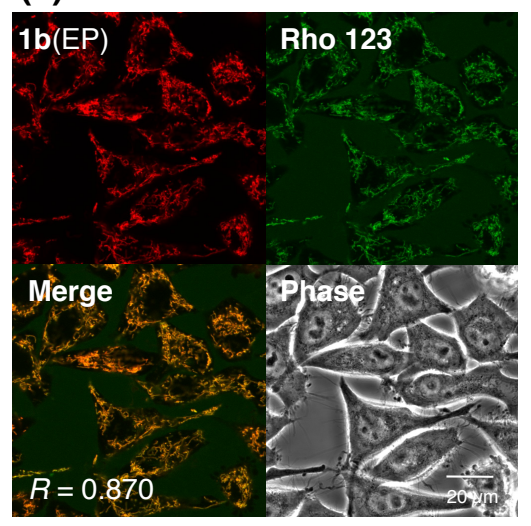

(d)

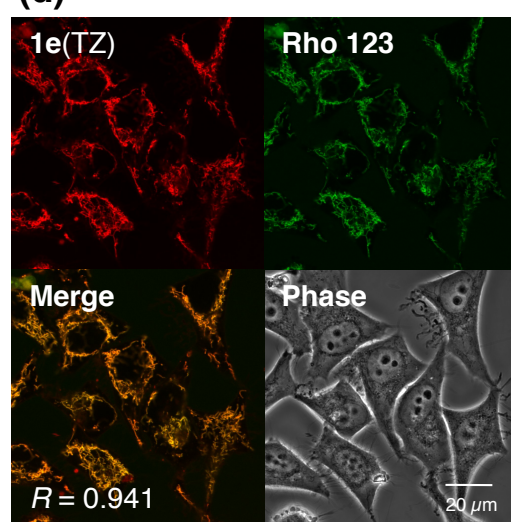

(b)

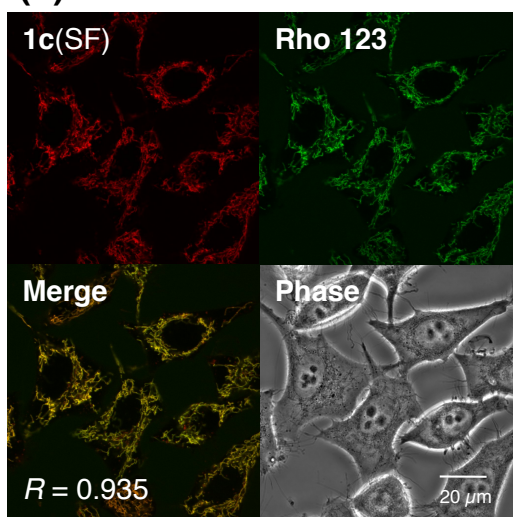

(e)

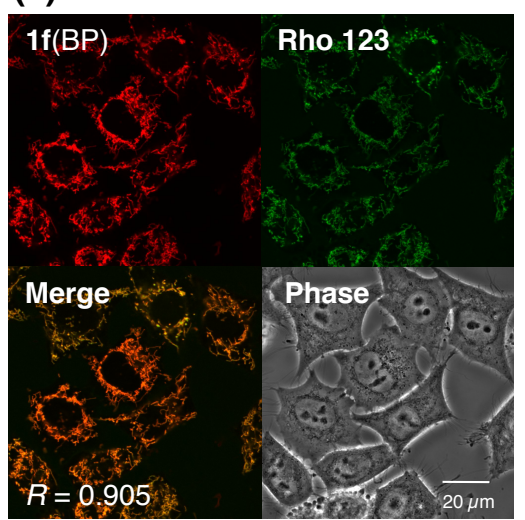

(c)

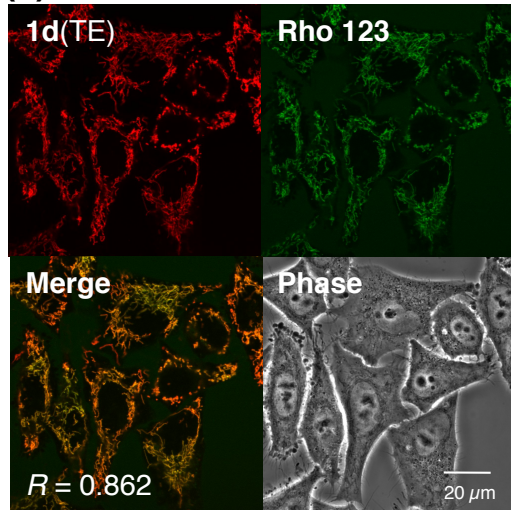

(f)

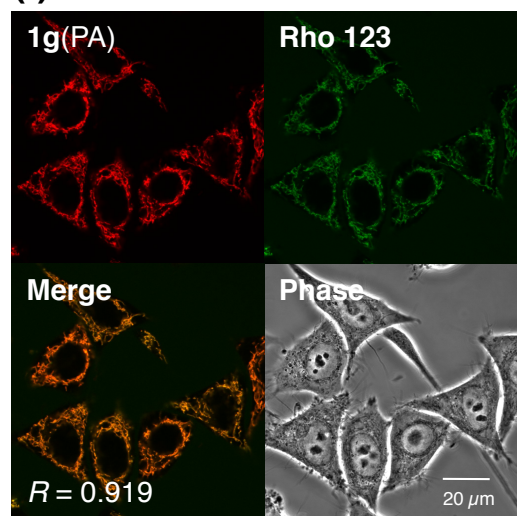

Figure S1. Confocal micrograph images of HeLa cells stained with (a) $\mathbf{1 b}(\mathrm{EP})$, (b) $\mathbf{1 c}(\mathrm{SF})$, (c) 1d(TE), (d) $\mathbf{1 e}(\mathrm{TZ}),(\mathrm{e}) \mathbf{1 f}(\mathrm{BP})$ and (f) $\mathbf{1 g}(\mathrm{PA})(1.0 \mu \mathrm{M})$ with Rhodamine $123(200 \mathrm{nM})$ at $37^{\circ} \mathrm{C}$ for $15 \mathrm{~min}$ in DMEM media. Colocalization was quantified using Pearson's correlation coefficient $(R)$. 
(a)

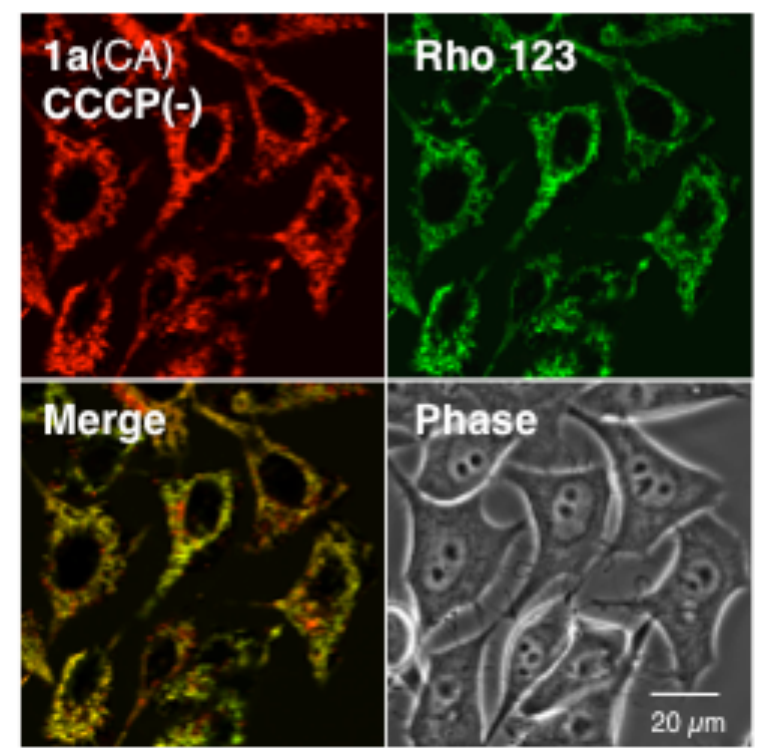

(b)

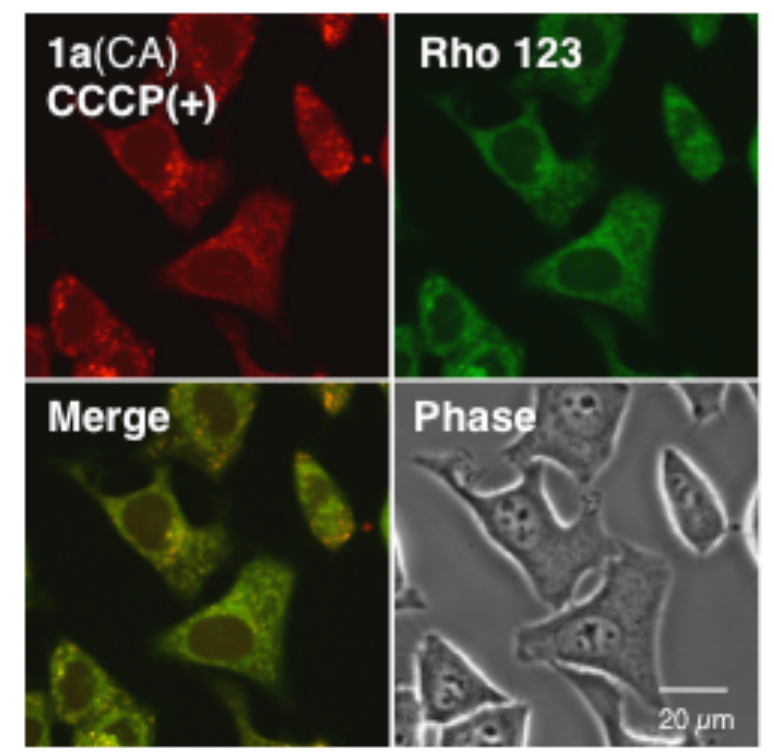

Figure S2. Confocal micrograph images of HeLa cells treated (a) without or (b) with CCCP $(5.0 \mu \mathrm{M})$, followed by $1 \mathbf{a}(\mathrm{CA})(1.0 \mu \mathrm{M})$ and Rhodamine $123(200 \mathrm{nM})$. 
(a)

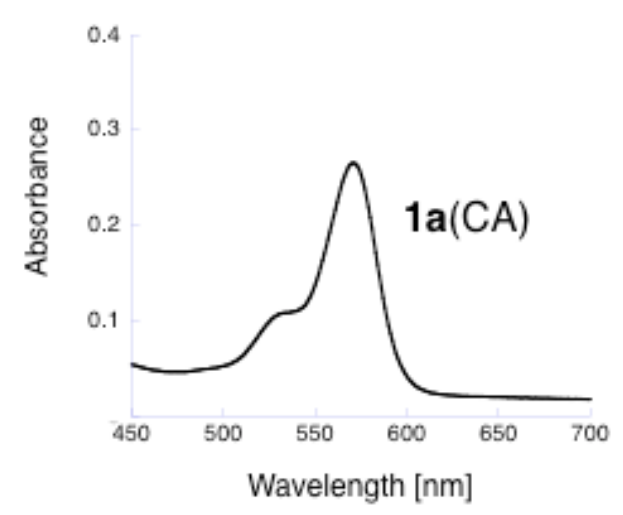

(b)

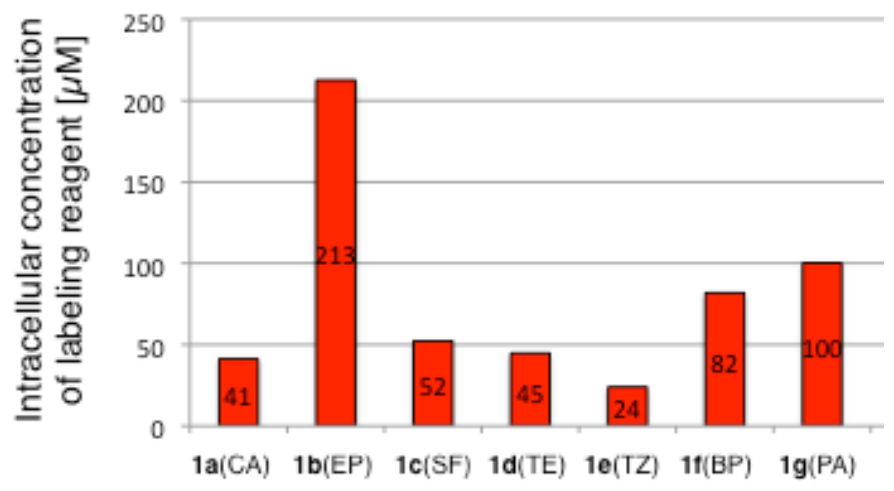

Figure S3. Intracellular concentration of MRMs (1a(CA)-19(PA)) in HeLa cells. (a) UV-Vis absorption spectrum of the lysate of $\mathbf{1 a}(\mathrm{CA})$-treated HeLa cells. The concentration of Et4-Rhod was determined by measuring the absorbance at $567 \mathrm{~nm}$ using the molar absorption coefficient of $96,100 \mathrm{~cm}^{-1} \mathrm{M}^{-1}$ (Ref S1). (b) Intracellular concentration of MRMs determined by this spectroscopic analysis. 


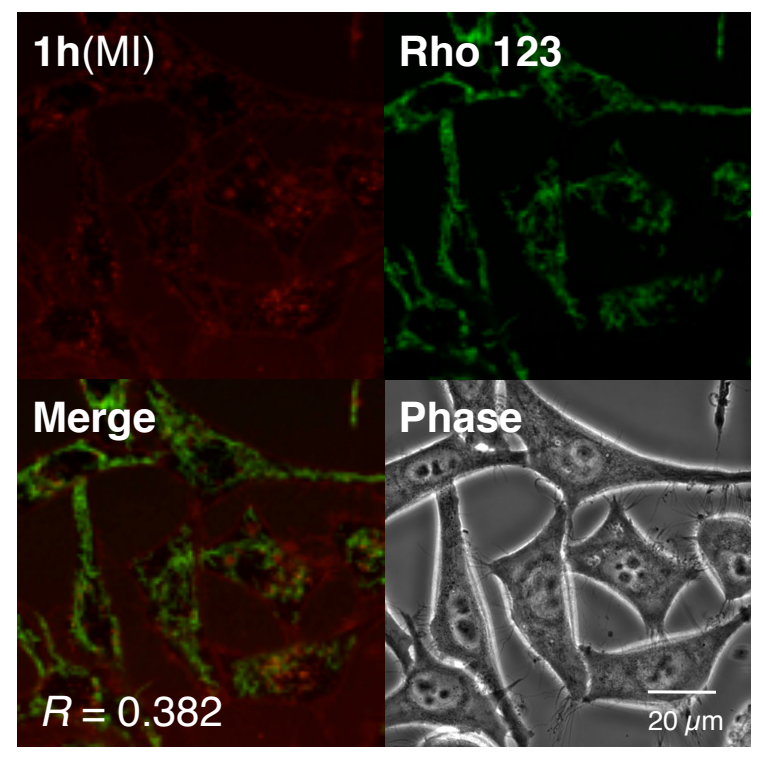

Figure S4. Confocal micrograph images of HeLa cells stained with $\mathbf{1 h}(\mathrm{MI})(1.0 \mu \mathrm{M})$ together with Rhodamine $123(200 \mathrm{nM})$ at $37^{\circ} \mathrm{C}$ for $15 \mathrm{~min}$ in DMEM media. Colocalization was quantified using Pearson's correlation coefficient $(R)$. 
(a)

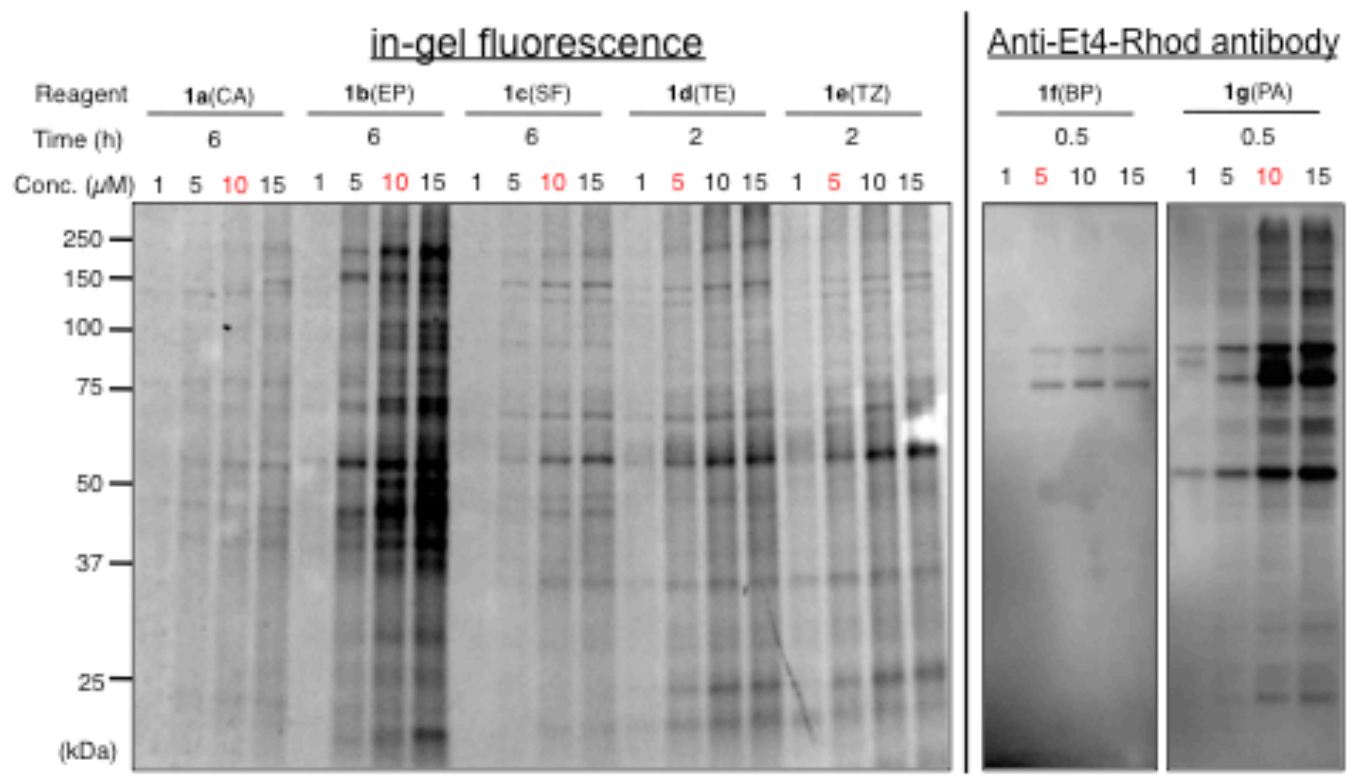

(b)

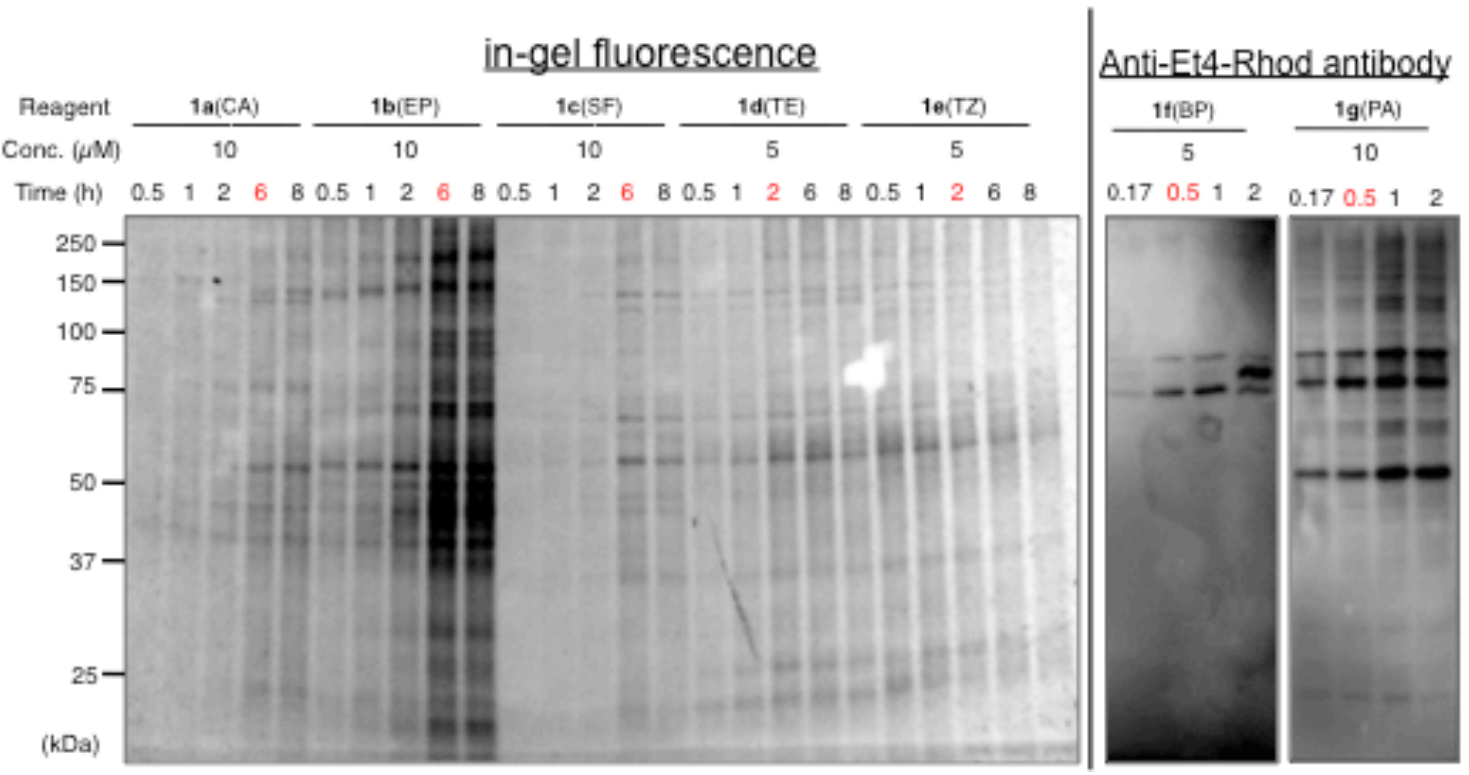

Figure S5. SDS-PAGE analysis of the (a) concentration and (b) time dependence of the labeling reaction with each MRM (1a-1g) in HeLa cells. HeLa cells were incubated with MRMs $(1-15 \mu \mathrm{M})$ in serum-free DMEM at $37{ }^{\circ} \mathrm{C}$ for $0.5-8 \mathrm{~h}$. In the case of $\mathbf{1 f}(\mathrm{BP})$ and $\operatorname{1g}(\mathrm{PA})$, the cells were then UV irradiated (40 min) on ice. After labeling, the cells were washed, lysed and analyzed by SDS-PAGE or western blotting with anti-Et4-Rhod antibody. Given the labeling efficiencies and the mitochondria localization of these MRMs, the optimal reaction condition was roughly determined for each MRM as follows: $\mathbf{1 a}(10 \mu \mathrm{M}, 6 \mathrm{~h}), \mathbf{1 b}(10$ $\mu \mathrm{M}, 6 \mathrm{~h}), \mathbf{1 c}(10 \mu \mathrm{M}, 6 \mathrm{~h}), \mathbf{1 d}(5 \mu \mathrm{M}, 2 \mathrm{~h}), \mathbf{1 e}(5 \mu \mathrm{M}, 2 \mathrm{~h}), \mathbf{1 f}(5 \mu \mathrm{M}, 0.5 \mathrm{~h}), \mathbf{1 g}(10 \mu \mathrm{M}, 0.5$ h). 


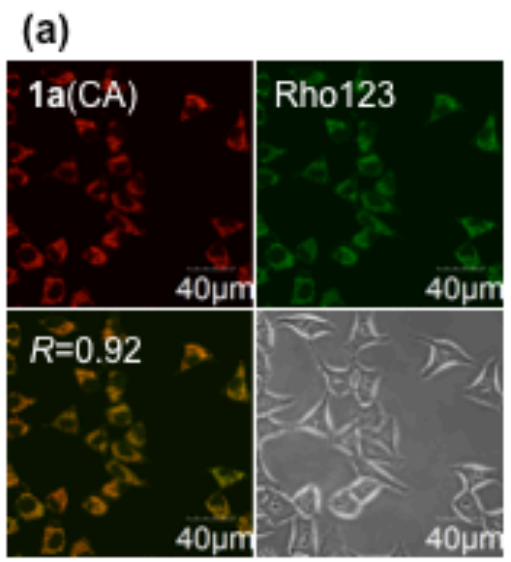

(b)

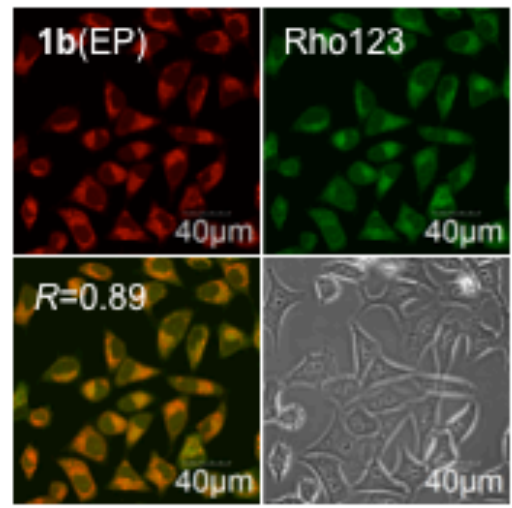

(d)

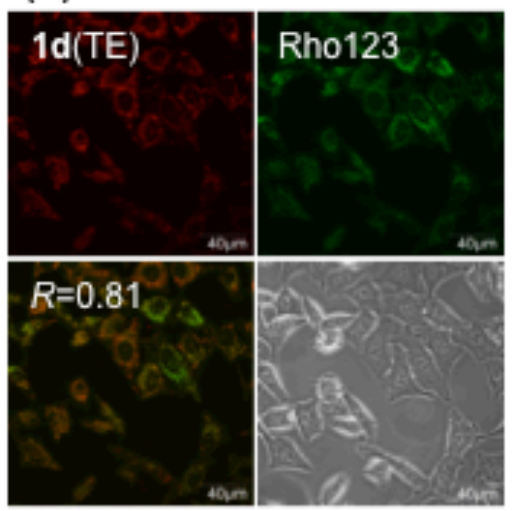

(e)

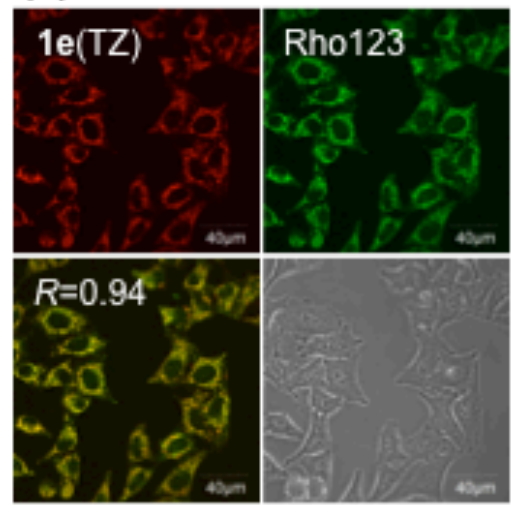

(c)
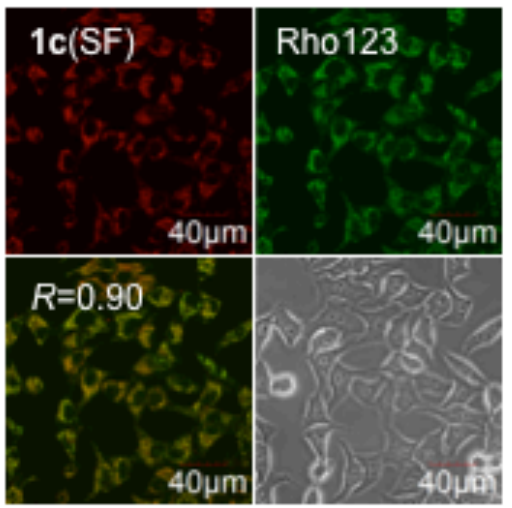

(f)

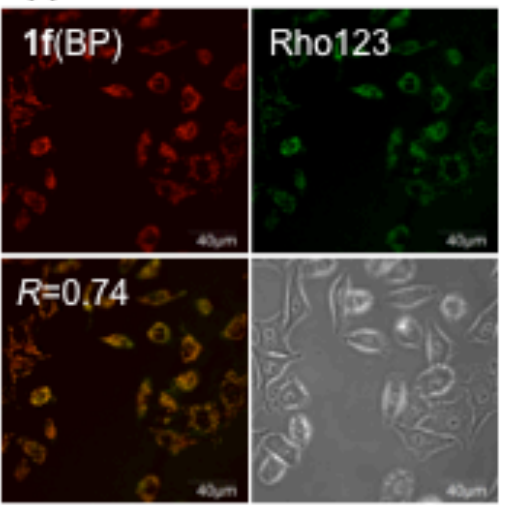

\section{(g)}
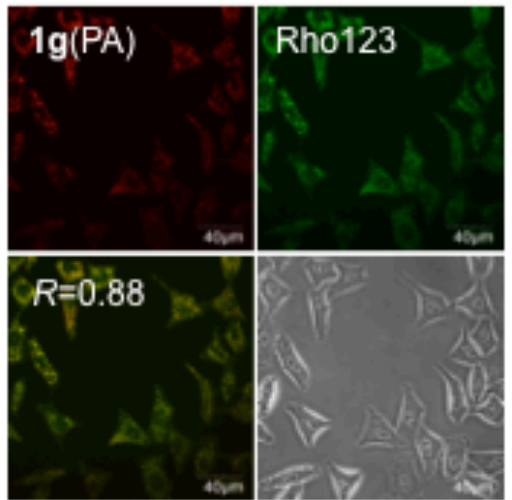

Figure S6. Confocal micrograph images of HeLa cells after incubation with (a) 1a $(10 \mu \mathrm{M}, 6$ h), (b) $\mathbf{1 b}(10 \mu \mathrm{M}, 6 \mathrm{~h})$, (c) $\mathbf{1 c}(10 \mu \mathrm{M}, 6 \mathrm{~h})$, (d) 1d (5 $\mu \mathrm{M}, 2 \mathrm{~h})$, (e) $\mathbf{1 e}(5 \mu \mathrm{M}, 2 \mathrm{~h})$, (f) $\mathbf{1 f}(5$ $\mu \mathrm{M}, 0.5 \mathrm{~h})$ or $(\mathrm{g}) \mathbf{1 g}(10 \mu \mathrm{M}, 0.5 \mathrm{~h})$, followed by Rhodamine $123(10 \mathrm{~min}, 200 \mathrm{nM})$. Colocalization was quantified using Pearson's correlation coefficient $(R)$. 


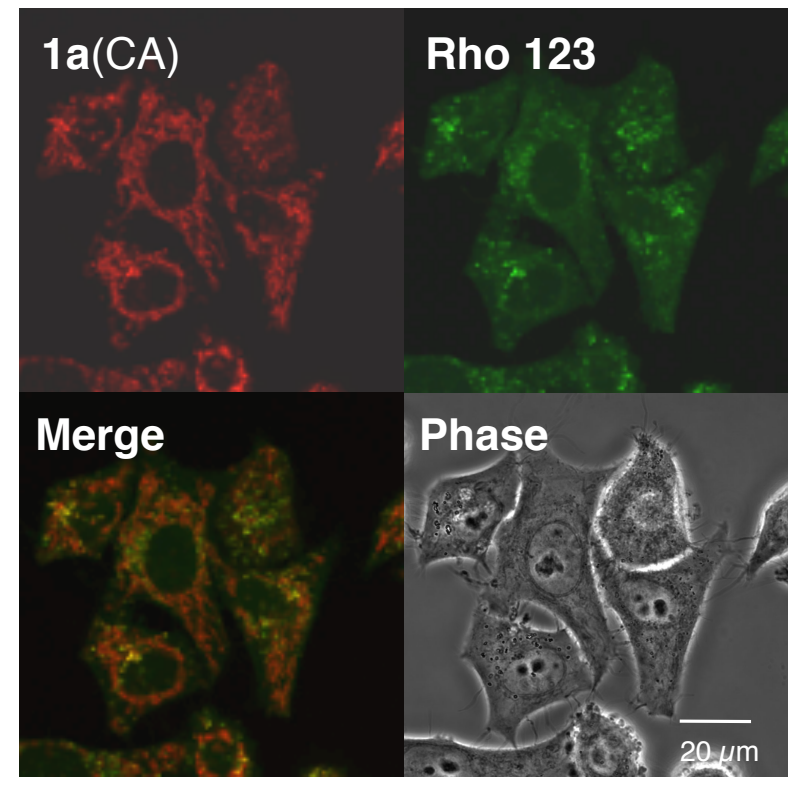

Figure S7. Confocal micrograph images of HeLa cells treated with 1a(CA) $(1.0 \mu \mathrm{M})$ and Rhodamine $123(200 \mathrm{nM})$ at $37^{\circ} \mathrm{C}$ for $15 \mathrm{~min}$, followed by CCCP $(5.0 \mu \mathrm{M})$ for $3 \mathrm{~min}$. 
(a)

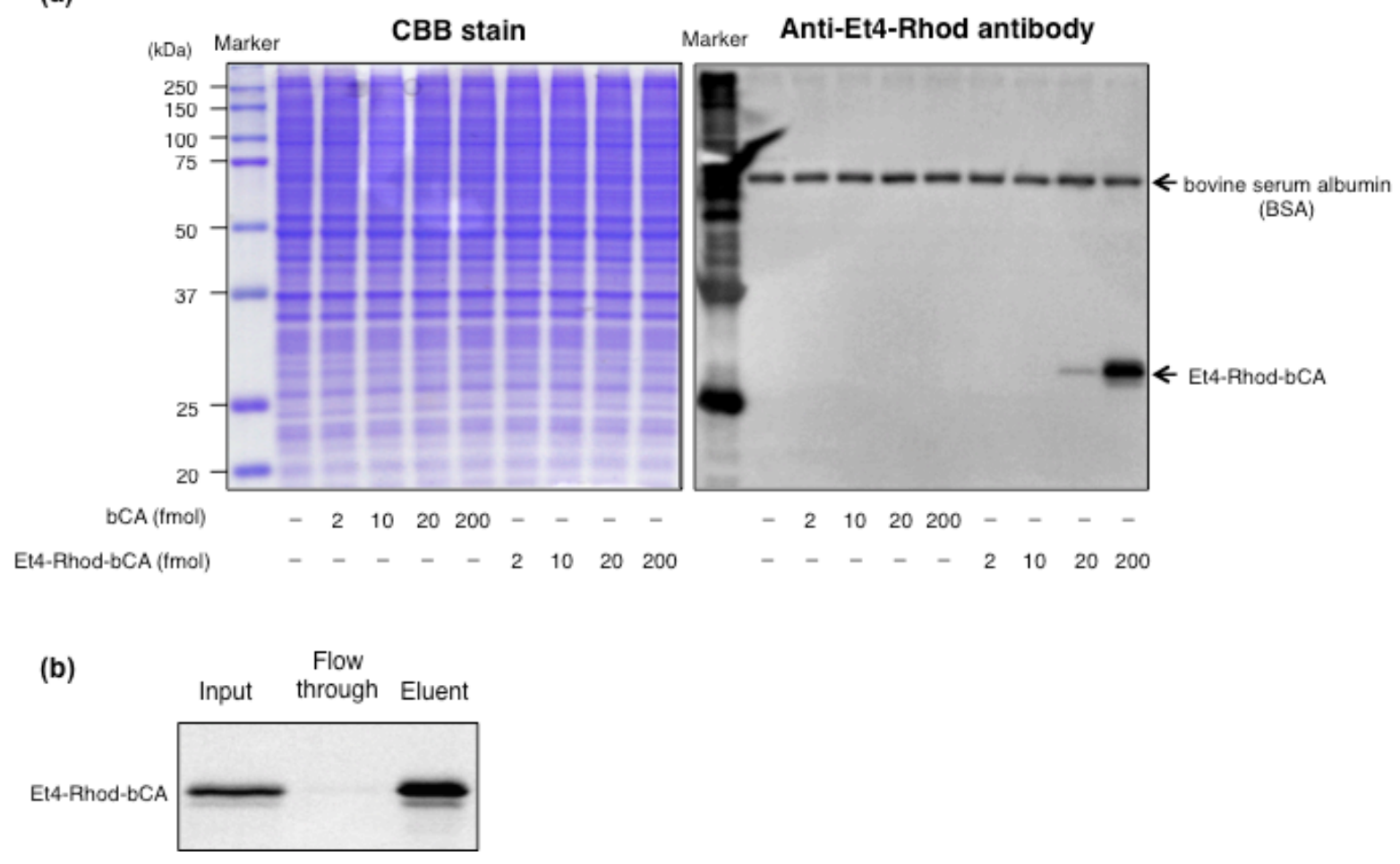

Figure S8. Evaluation of the performance of our homemade anti-Et4-Rhod antibody. (a) Detection sensitivity and selectivity assay. Et4-Rhod-modified bovine carbonic anhydrase (bCA) (50\% in the modification ratio) was prepared by reaction with $1 \mathbf{d}(\mathrm{TE})$, and the corresponding amount of the protein were mixed with HeLa cell lysate. These samples were resolved by SDS-PAGE, transferred to PVDF membrane, and immunoblotted with the anti-Et4-Rhod antibody. $20 \mathrm{fmol}$ of the Et4-Rhod-bCA (that is $\sim 10 \mathrm{fmol}$ of Et4-Rhod modified protein) at the minimum was detected. Note that bovine serum albumin (BSA) derived from the serum of cell culture media was also detected in all lanes. This is because our anti-Et4-Rhod antibody was prepared via immunizing a rabbit with the Et4-Rhod-BSA conjugate, generating a mixture of the anti-Et4-Rhod antibody and the anti-BSA antibody. In this study, we used the serum fraction without any purification. Nonetheless, any bands other than the Et4-Rhod-bCA and BSA were not observed in the blots, which demonstrated the high selectivity of the anti-Et4-Rhod antibody. (b) Enrichment of the Et4-Rhod-bCA conjugate with the anti-Et4-Rhod antibody. The Et4-Rhod-bCA conjugate (100 pmol) was immunoprecipitated with the anti-Et4-Rhod antibody, and detected by in-gel fluorescence 
imaging. A clear band due to the enriched Et4-Rhod-bCA conjugate was observed in the eluent fraction, whereas no noticeable band was detected in the flow through. This result indicates the high capacity of the anti-Et4-Rhod antibody to enrich the Et4-Rhod modified proteins. 
(a)

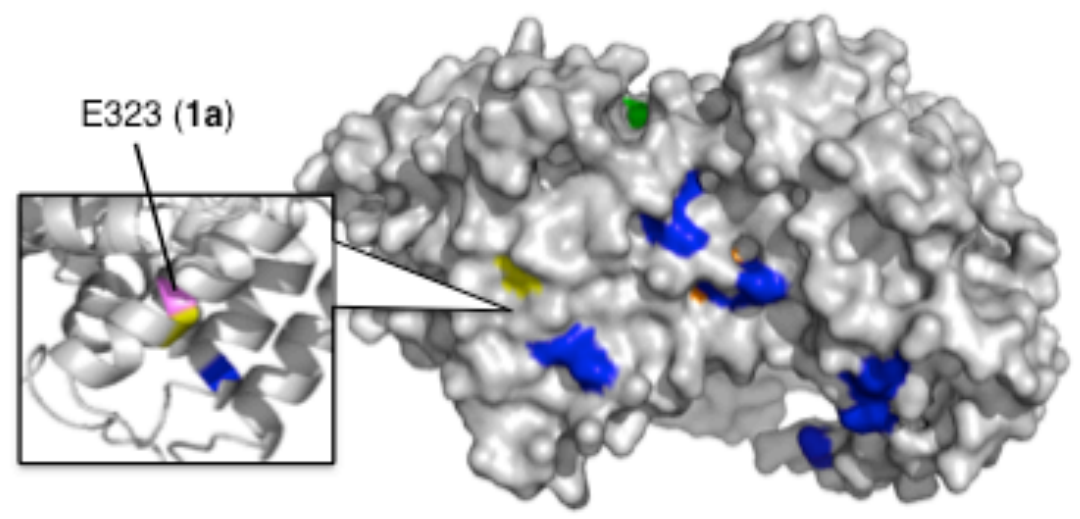

(b)

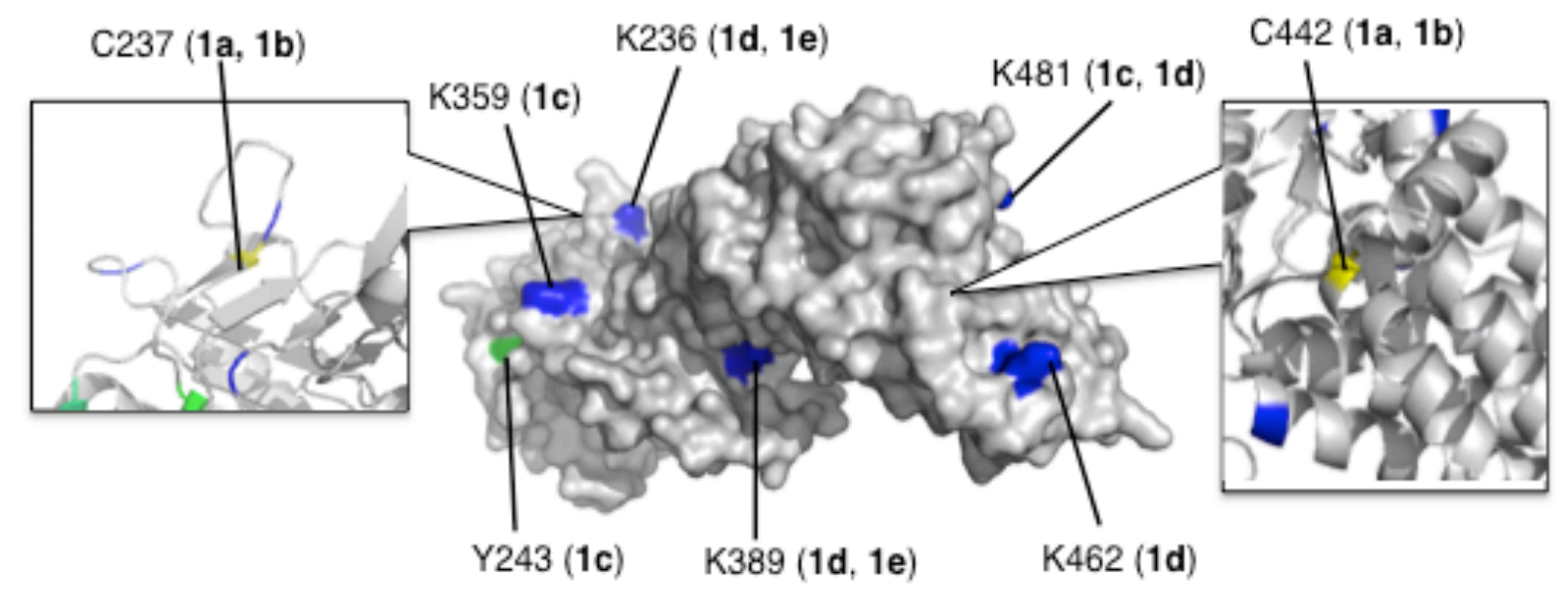

(c)

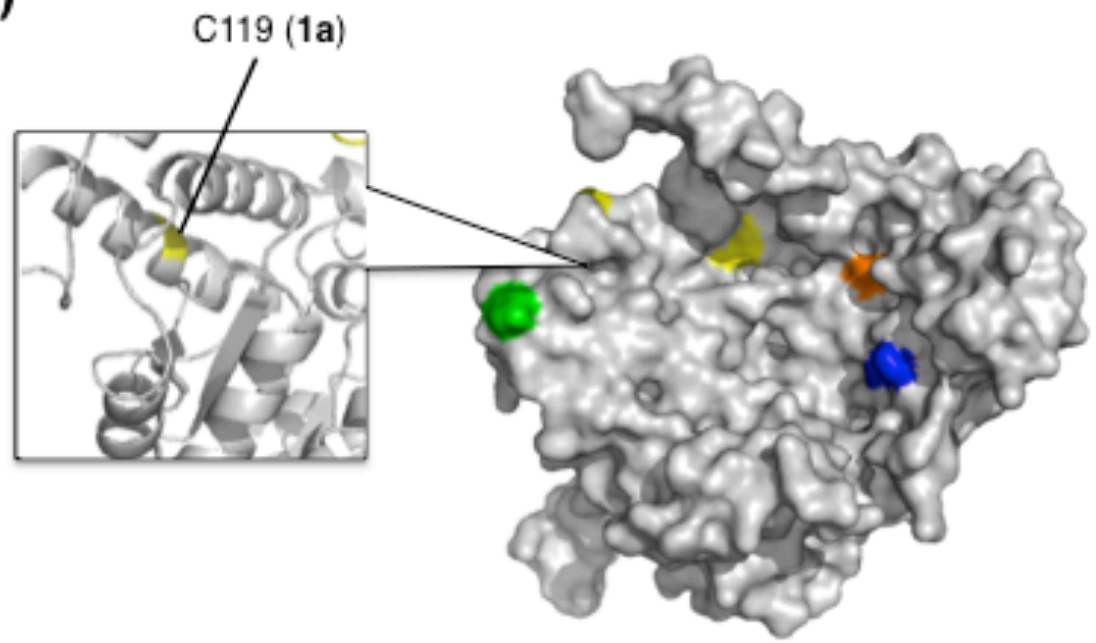

Figure S9. Sphere models of representative proteins labeled by MRMs (see also Figure 3 in the main text). Et4-Rhod labeled residues are colored. Protein models from SWISS-MODEL ${ }^{\text {S2 }}$ or crystal structures from Protein Data Bank (PDB) were manipulated and rendered in PyMOL. (a) Trifunctional enzyme subunit alpha, mitochondrial (HADHA). E323 
labeled by $\mathbf{1 a}$ is buried inside the protein. K60 labeled by $\mathbf{1 c}(\mathrm{SF})$ was not contained in this model. (b) $60 \mathrm{kDa}$ heat shock protein, mitochondrial (HSP60) [SWISS-MODEL]. The labeled residues C237 (1a, 1b) and C442 (1a, 1b) are buried inside the protein. (c) Serine hydroxymethyltransferase, mitochondrial (SHMT2) [SWISS-MODEL]. C16 labeled by 1a is not contained in this model. C119 labeled by 1a is buried inside the protein. 
(a)

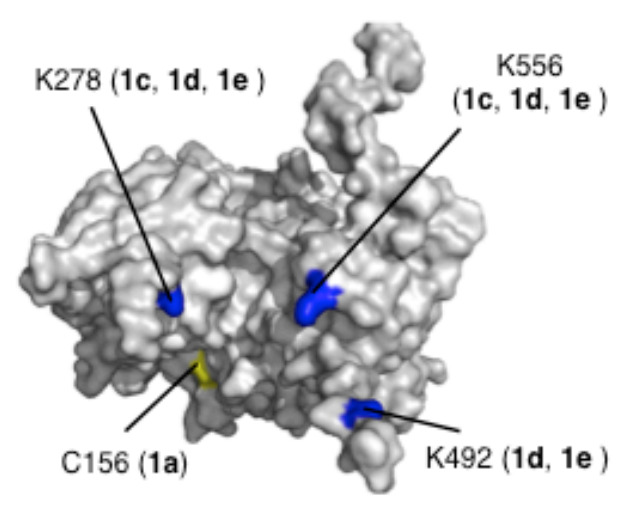

(c)

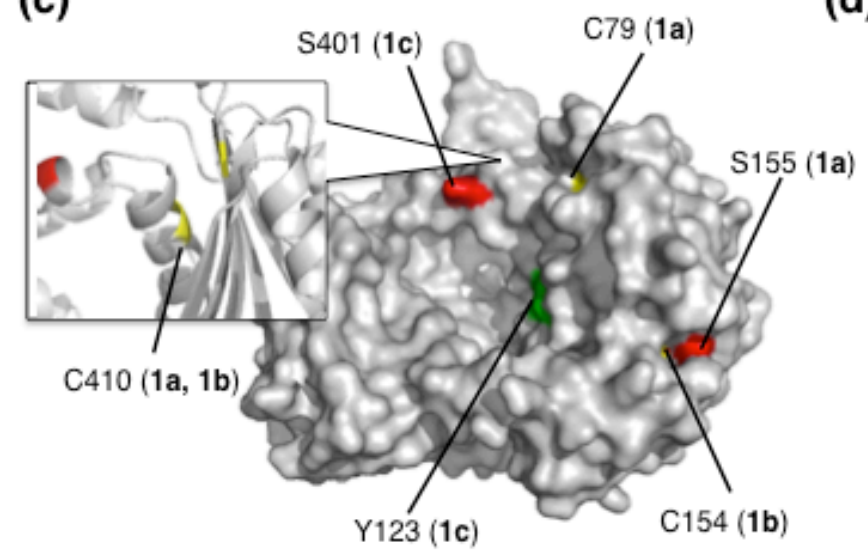

(b)

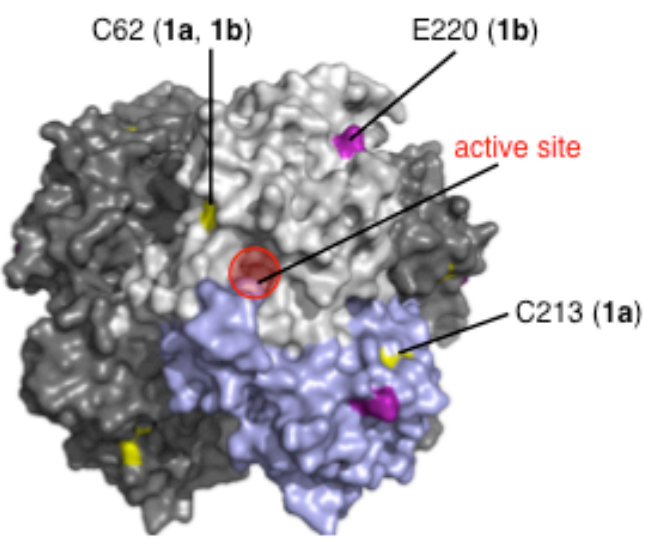

(d)

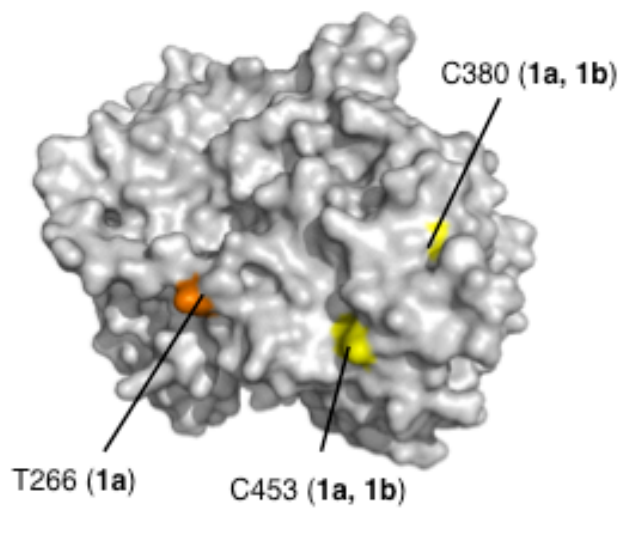

(e)

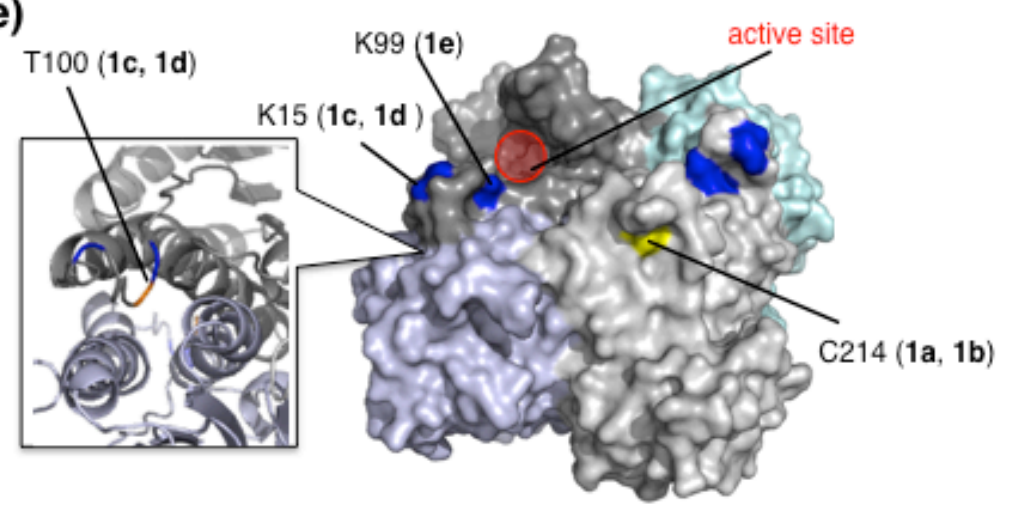

Figure S10. Sphere models of representative proteins labeled by MRMs. Et4-Rhod labeled residues are colored. (a) Very long-chain specific acyl-CoA dehydrogenase, mitochondrial (ACADVL) [PDB ID: 2UXW]. (b) Enoyl-CoA hydratase, mitochondrial (ECHS1) (hexamer) [PDB : 2HW5]. (c, d) Cytochrome b-c1 complex subunit 1, mitochondrial (UQCRC1) [SWISS-MODEL]. The labeled residue C410 (1a, 1b) is buried inside the protein. (e) 3-hydroxyacyl-CoA dehydrogenase type-2 (HCD2) (tetramer) [SWISS-MODEL]. The labeled residue T100 (1c, $1 \mathbf{d})$ is buried inside the protein. 
(a)

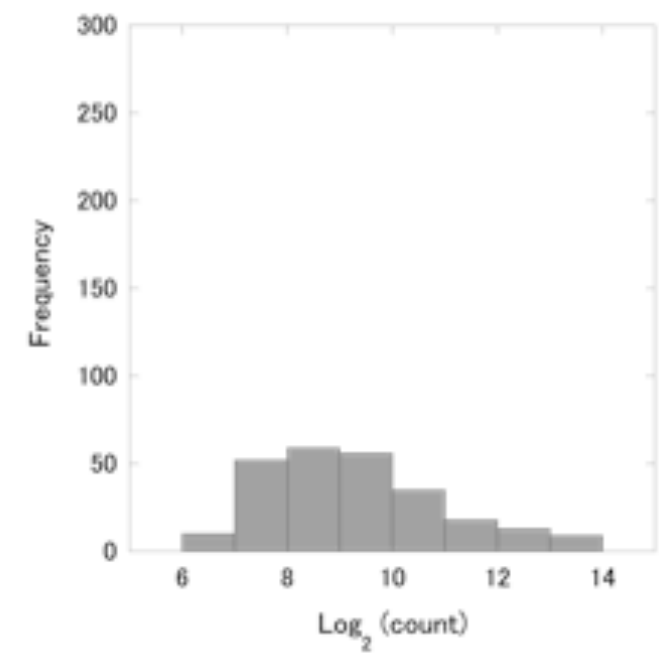

(b)

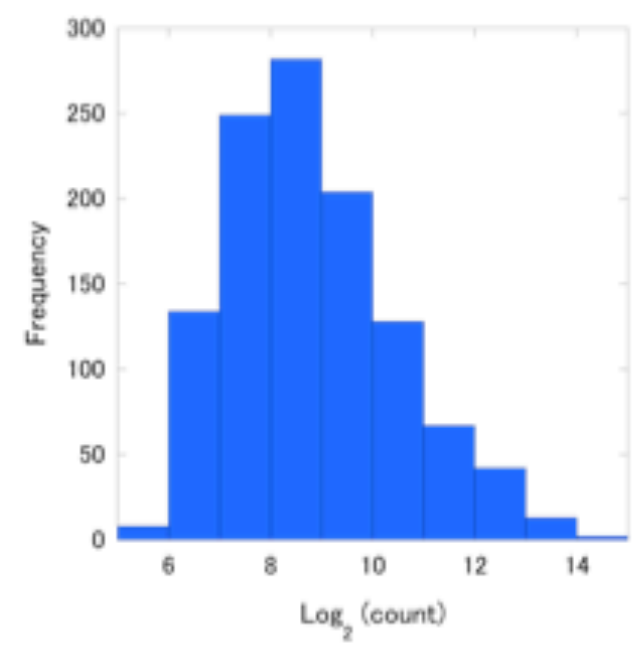

(c)

\begin{tabular}{|c|c|c|c|}
\hline $\log _{2}$ value & $\begin{array}{c}\text { Number of identified } \\
\text { mitochondrial } \\
\text { proteins (Identified) }\end{array}$ & $\begin{array}{c}\text { Number of whole } \\
\text { mitochondrial } \\
\text { proteins (Whole) }\end{array}$ & $\begin{array}{c}\text { Identified/ } \\
\text { Whole }\end{array}$ \\
\hline $\begin{array}{c}5-8 \\
\text { (low-abundance proteins) }\end{array}$ & 62 & 391 & 0.16 \\
\hline $\begin{array}{c}8-11 \\
\text { (middle-abundance proteins) }\end{array}$ & 150 & 614 & 0.24 \\
\hline $\begin{array}{c}11-15 \\
\text { (high-abundance proteins) }\end{array}$ & 40 & 124 & 0.32 \\
\hline
\end{tabular}

Figure S11. Correlation of the MRM-identified proteins with the abundance of mitochondrial proteins. (a) Histogram of mitochondrial proteins identified in this study against the mitochondrial gene expression level. (b) Histogram of gene expression levels of whole mitochondrial proteins registered in MitoCarta database. ${ }^{\mathrm{S} 3}$ We analyzed the expression level of individual mitochondrial proteins using a database of whole mRNA expression profile of HeLa cells (See also Supplementary data S6) ${ }^{\mathrm{S} 4}$ In our analysis, proteins are divided into three fractions based on the $\log _{2}$ values of mRNA signal intensities in the database, that is "5-8", "8-11" and "11-15" as low-, middle-, and high-abundance proteins, respectively. According to this classification, we categorized proteins and calculated a ratio of the number of identified proteins to that of whole mitochondrial proteins (c). This analysis revealed that a positive correlation between the ratio and protein abundance, which indicates high-abundance proteins tend to be more labeled and enriched with our MRM-based method. 


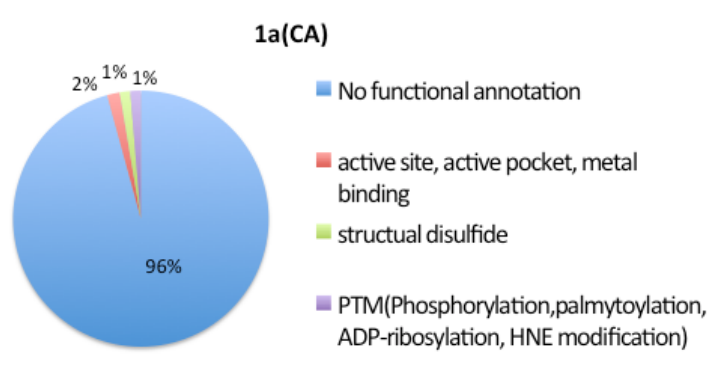

$1 \mathrm{c}(\mathrm{SF})$

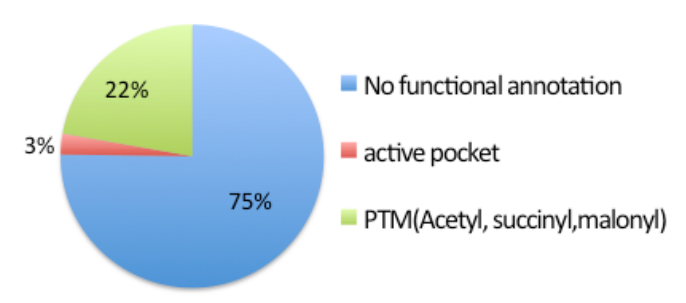

$1 \mathrm{e}(\mathrm{TZ})$

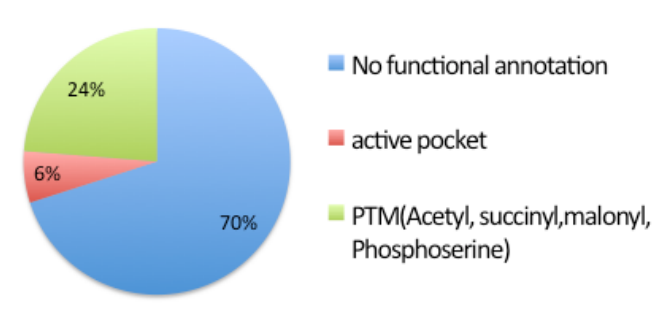

$1 \mathrm{~b}(\mathrm{EP})$

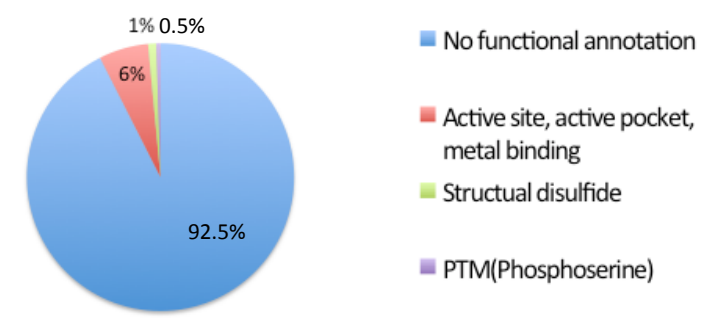

$1 \mathrm{~d}(\mathrm{TE})$

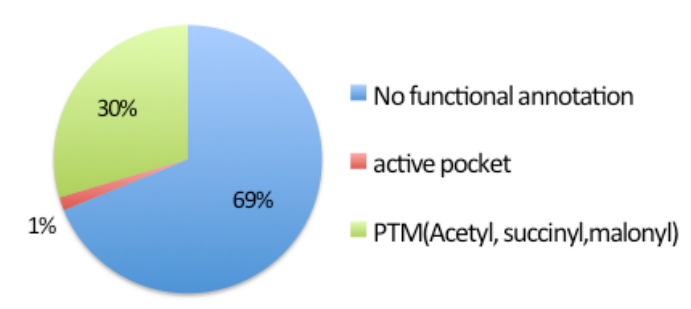

Figure S12. Pie charts illustrating the ratio of functionally annotated residues among labeled ones. Amino acid annotation in the "Function" and "PTM/Processing" section of the relevant UniProt (Universal Protein Resource) entry was manually explored from Supplementary data S1 and any annotation corresponding to the labeled residue was collected. This data revealed that the protein labeling with MRMs was predominantly independent on the protein activity/affinity. 
(a)

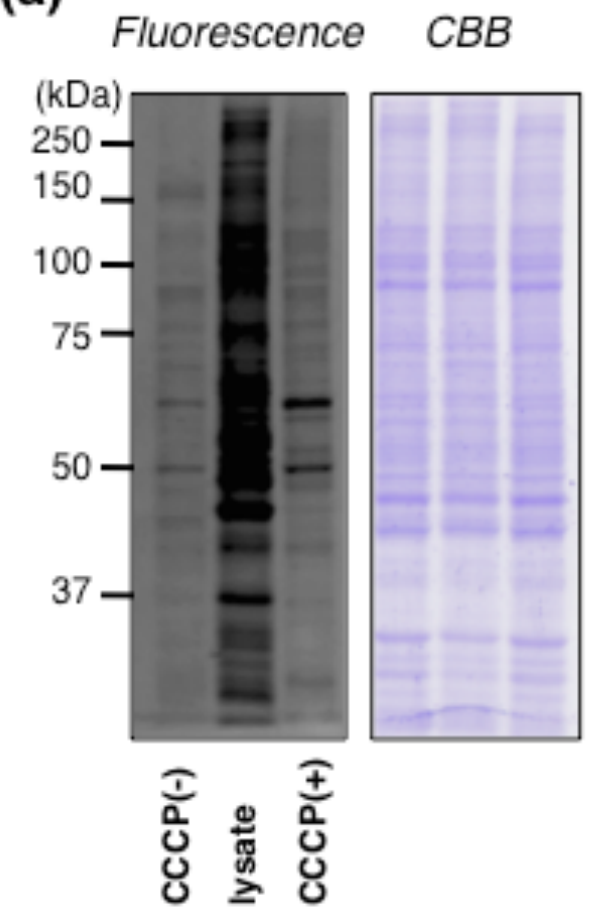

(b)

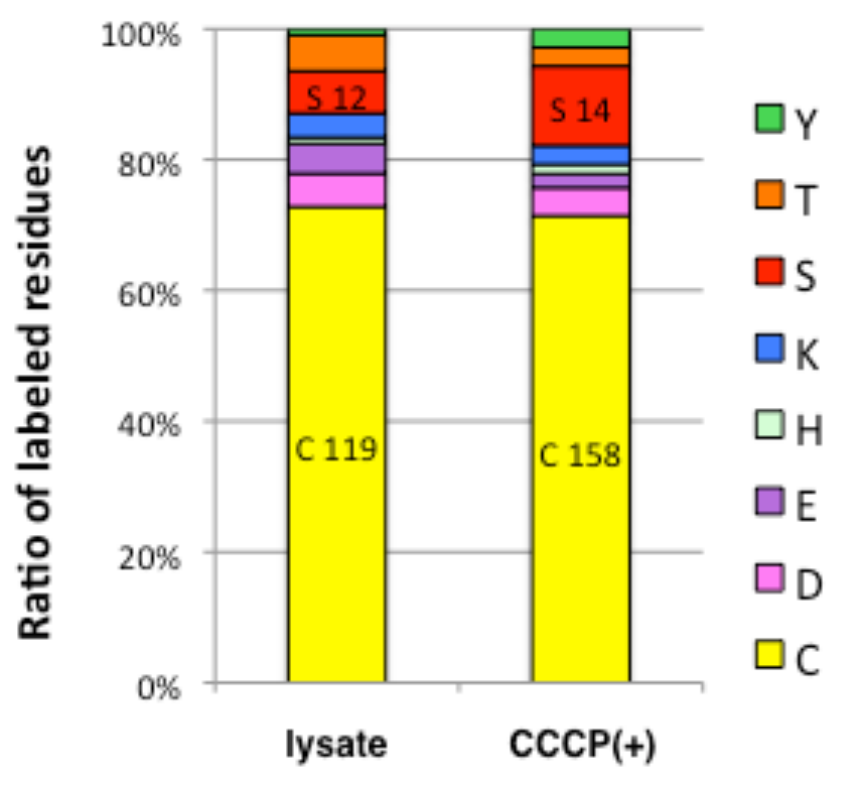

Figure S13. Comparing a positive control ( $\mathrm{CCCP}(-)$ condition) with negative control experiments using HeLa cell lysate and CCCP-pretreated HeLa cells. CCCP (-) condition: HeLa cells were incubated with $\mathbf{1 a}(\mathrm{CA})(10 \mu \mathrm{M})$ in serum-free DMEM at $37^{\circ} \mathrm{C}$ for $6 \mathrm{~h}$. After labeling, the cells were washed with PBS and lysed. Lysate condition: HeLa cells were lysed, and the lysate $\left(3 \mathrm{mg} / \mathrm{mL}\right.$ protein) was incubated with $1 \mathrm{a}(\mathrm{CA})(10 \mu \mathrm{M})$ at $37^{\circ} \mathrm{C}$ for $6 \mathrm{~h}$. CCCP $(+)$ condition: HeLa cells were incubated with $\mathrm{CCCP}(5.0 \mu \mathrm{M})$ at $37{ }^{\circ} \mathrm{C}$ for $5 \mathrm{~min}$, followed by $1 \mathbf{a}(\mathrm{CA})(10 \mu \mathrm{M})$ for $6 \mathrm{~h}$. After labeling, the cells were washed with PBS and lysed. (a) In-gel fluorescence and Coomassie Brilliant Blue (CBB) stain of SDS-PAGE gels. Equal amounts of proteins $(8.0 \mu \mathrm{g})$ were loaded onto $10 \%$ acrylamide gels. (b) Amino acid preference of $1 \mathbf{a}(\mathrm{CA})$ determined by LC-MS/MS analyses. 
(a)

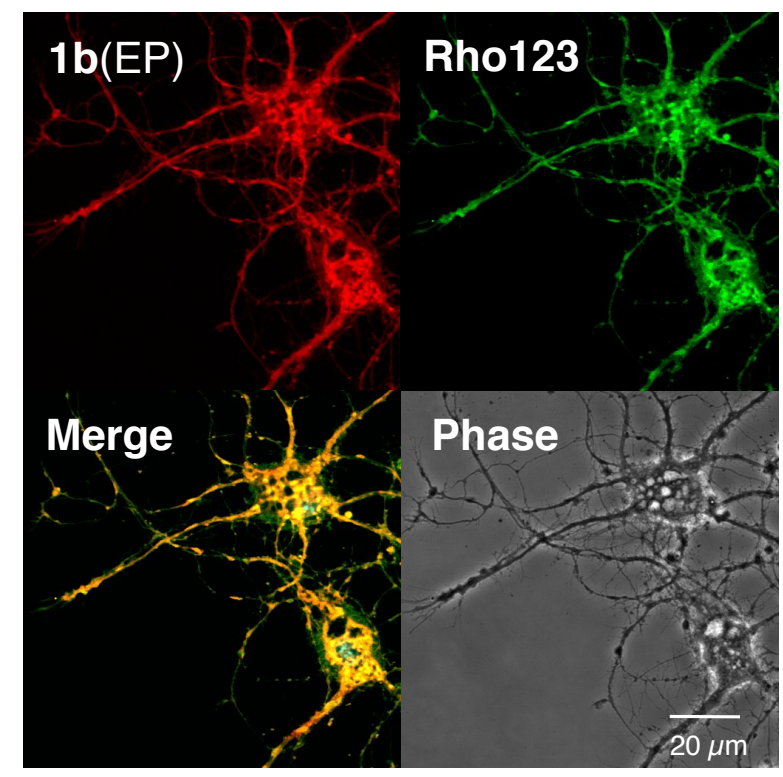

(c)

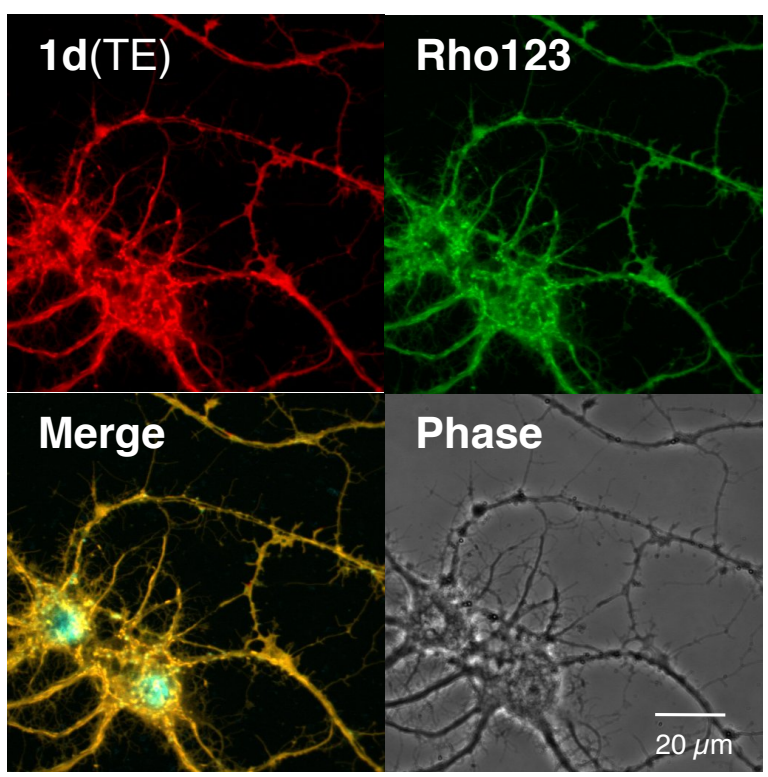

(b)

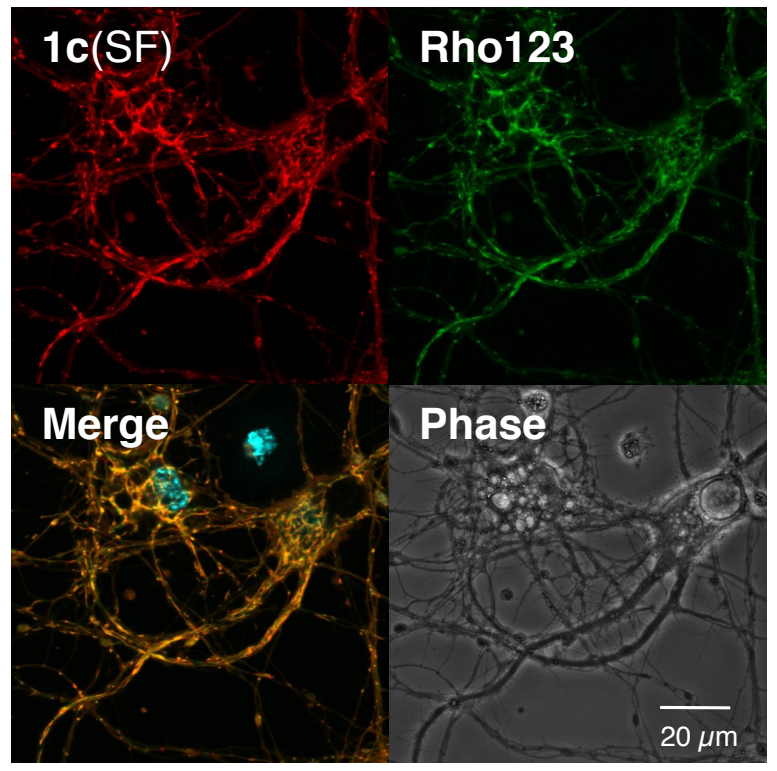

(d)

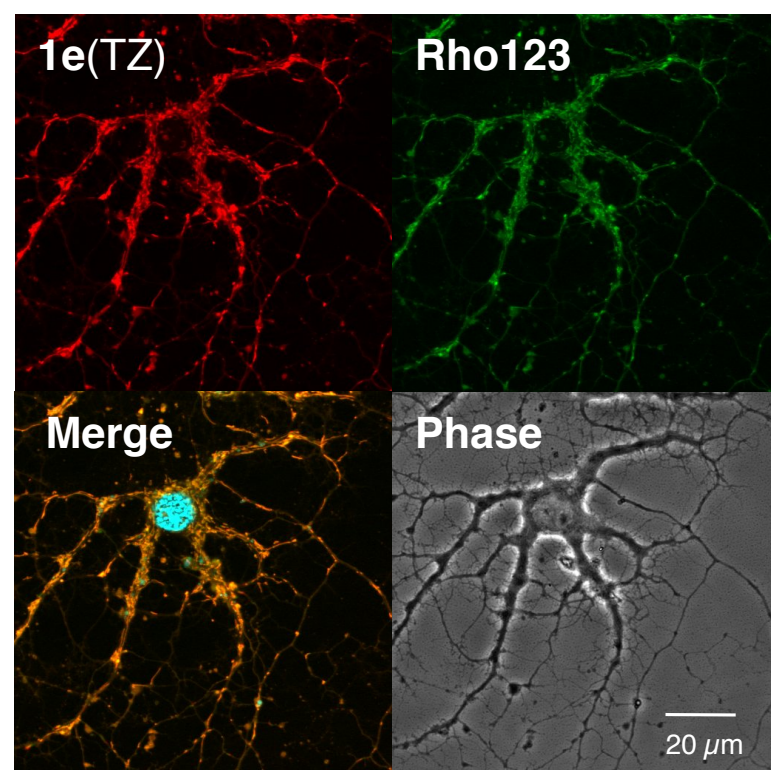

Figure S14. Confocal micrograph images of rat cerebral cortex cells stained with (a) $\mathbf{1 b}(\mathrm{EP})$, (b) $1 \mathrm{c}(\mathrm{SF})$, (c) $1 \mathrm{~d}(\mathrm{TE})$ and (d) $1 \mathrm{e}(\mathrm{TZ})(1.0 \mu \mathrm{M})$ with Rhodamine $123(200 \mathrm{nM})$ and Hoechst33342 $(1.0 \mu \mathrm{M})$ at $37^{\circ} \mathrm{C}$ for $15 \mathrm{~min}$ in DMEM media. 


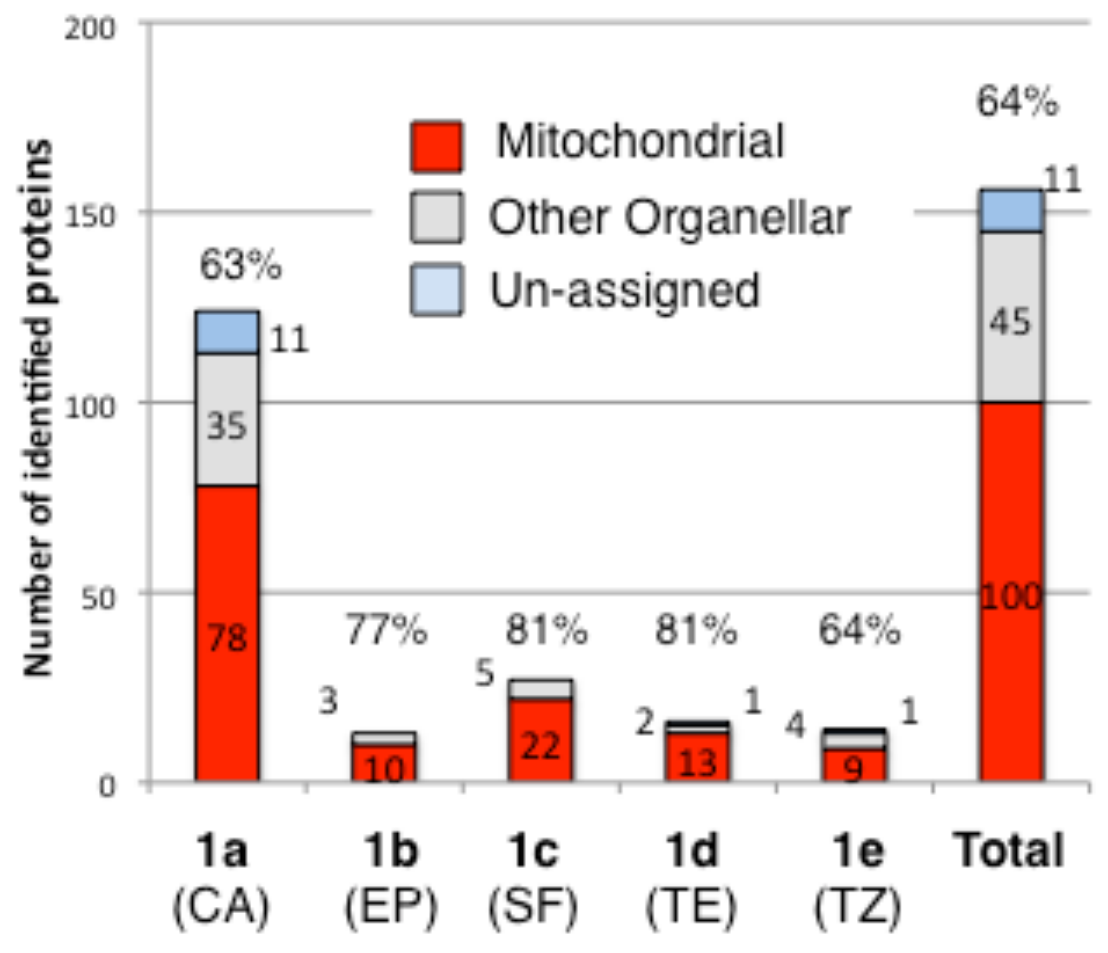

Figure S15. The number of proteins identified by LC-MS/MS analysis from brain (cerebrum) slices, and the ratio of mitochondrial proteins. 


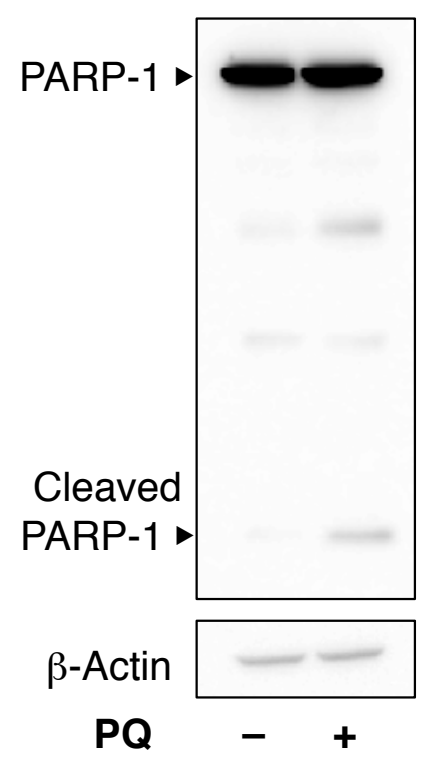

Figure S16. Western blotting analysis of PARP-1 cleavage. HeLa cells were incubated in culture medium without or with PQ $(100 \mu \mathrm{M})$ for $48 \mathrm{~h}$ at $37{ }^{\circ} \mathrm{C}$. Cells were lysed and analyzed by Western blotting with antibodies against PARP-1 and $\beta$-Actin. 

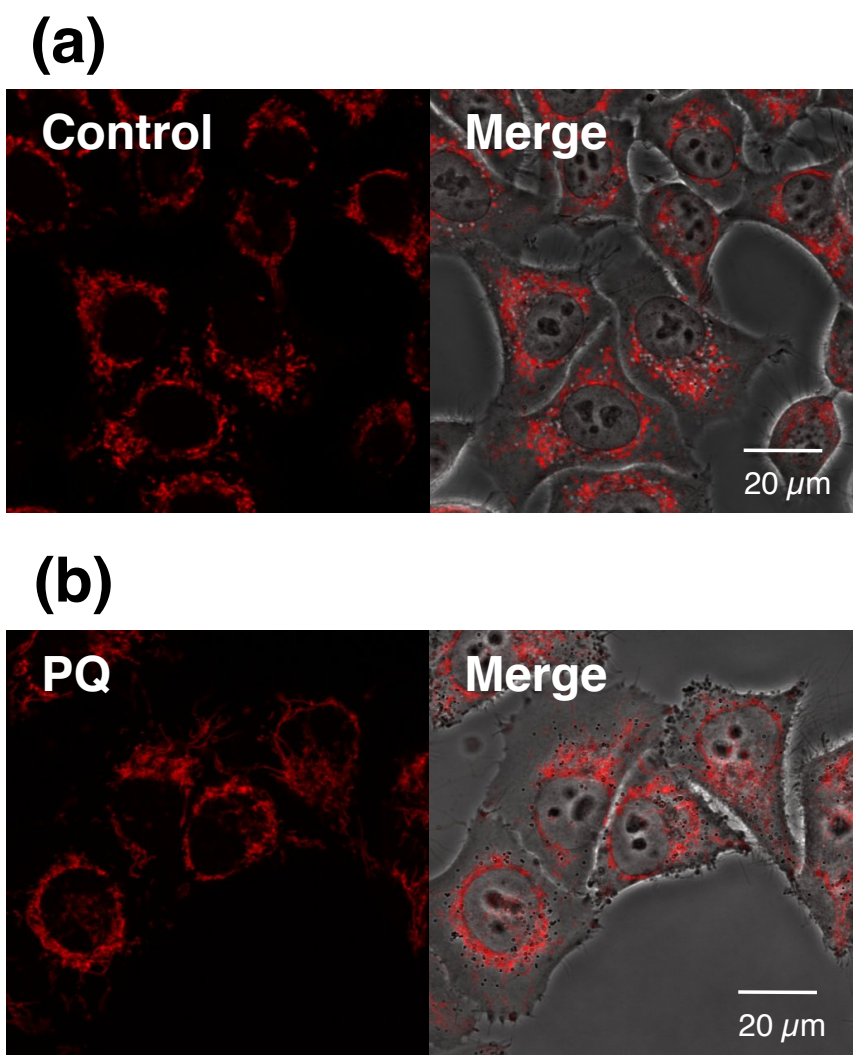

Figure S17. Confocal micrograph images of HeLa cells treated (a) without (control) or (b) with PQ $(100 \mu \mathrm{M})$ for $48 \mathrm{~h}$, followed by $1 \mathrm{a}(\mathrm{CA})(5.0 \mu \mathrm{M})$ for $6 \mathrm{~h}$ in serum-free SILAC medium. 


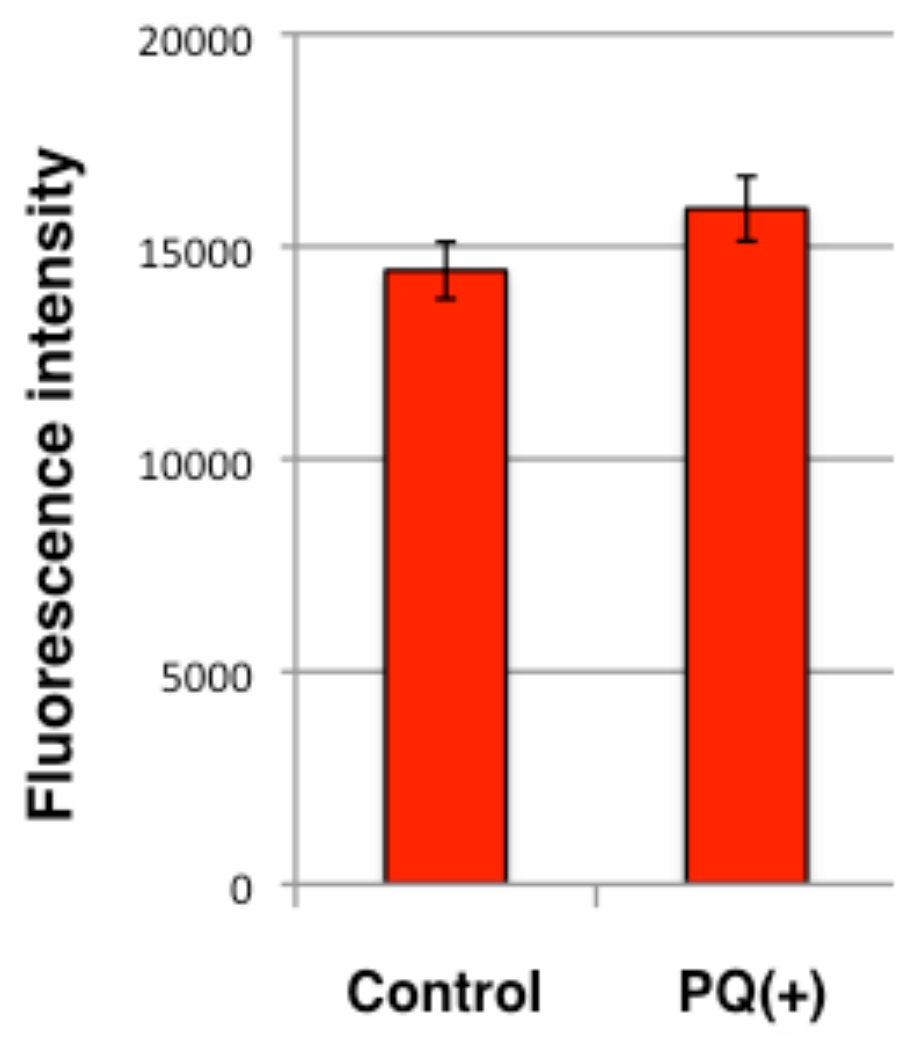

Figure S18. Intracellular fluorescence intensity of $1 \mathrm{a}(\mathrm{CA})$ measured by fluorescence microscope imaging. HeLa cells were treated without (control) or with PQ $(100 \mu \mathrm{M})$ for $48 \mathrm{~h}$, followed by $1 \mathbf{a}(\mathrm{CA})(5.0 \mu \mathrm{M})$ for $6 \mathrm{~h}$ in serum-free SILAC medium. The fluorescent intensities of Et4-Rhod over the entire cells ( $n=20$ cells) were quantified. Error bars show \pm standard error. 


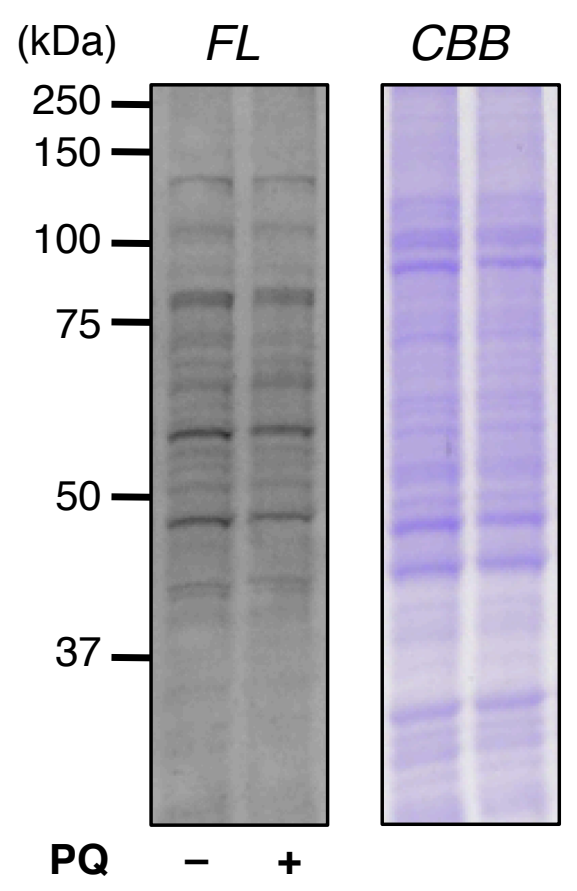

Figure S19. SDS-PAGE analysis by in-gel fluorescence imaging and CBB staining. PQ-treated $(100 \mu \mathrm{M}, 48 \mathrm{~h})$ or non-treated HeLa cells were incubated with 1a (CA) $(5.0 \mu \mathrm{M})$ in serum-free SILAC medium at $37{ }^{\circ} \mathrm{C}$ for $6 \mathrm{~h}$. After labeling, the cells were washed, lysed and analyzed by SDS-PAGE. 


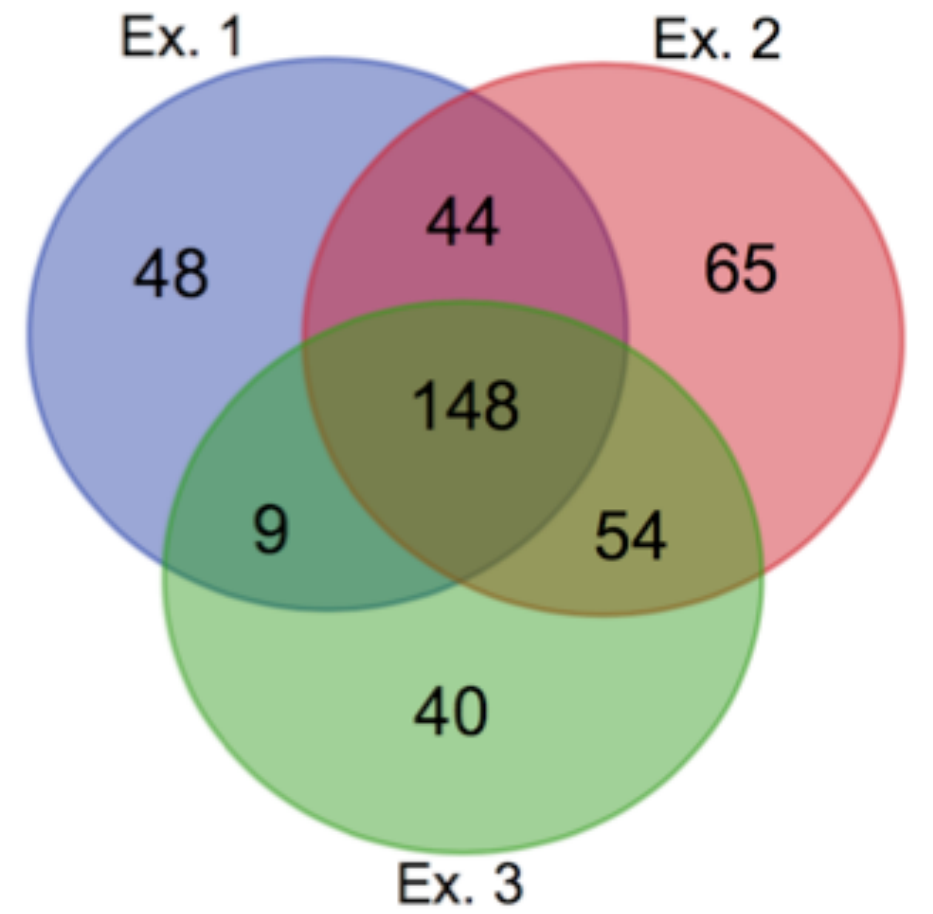

Figure S20. Venn diagram representing the overlap in the number of proteins identified from the three independent SILAC experiments. Proteins detected twice (at least) were selected as identified proteins (255 proteins) with a high confidence, and used for the quantitative analysis. 


\section{$\geq 2$ fold up-regulated proteins}

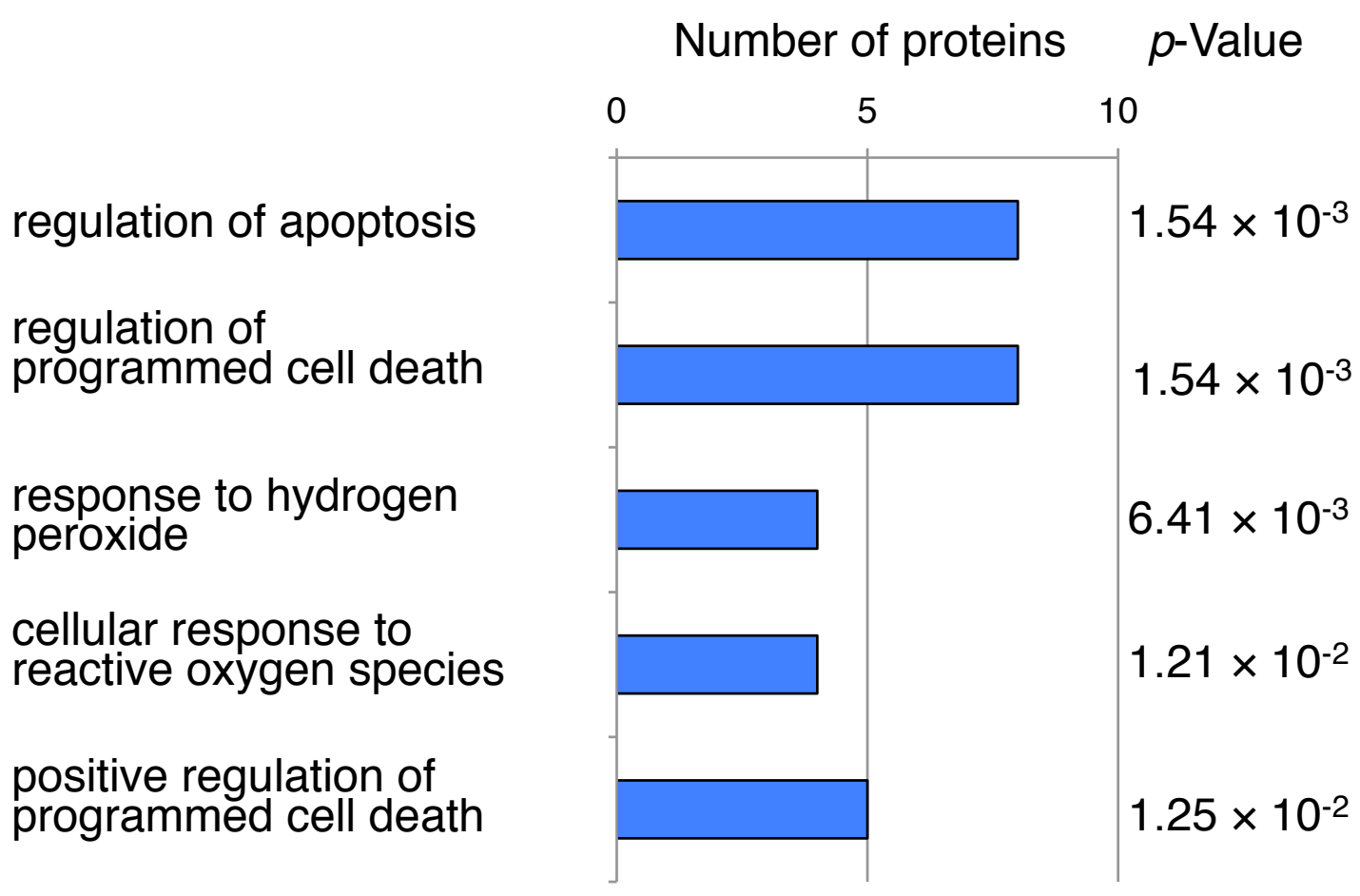

Figure S21. Functional classification of up-regulated proteins with a 2-fold change in our SILAC experiment (also see Figure 6 in the main text and Table S8). The functional annotation analysis was performed using DAVID Bioinformatics Resources. Briefly, all up-regulated proteins ( $>2$-fold) were queried against 255 proteins identified in the SILAC experiments as a background. 
Table S1. The number (and ratio) of Et4-Rhod-labeled residues of identified peptides in

HeLa cells.

\begin{tabular}{|c|c|c|c|c|c|c|c|c|c|}
\hline MRMs & $\mathrm{C}$ & D & $\mathrm{E}$ & $\mathrm{H}$ & $\mathrm{K}$ & $\mathrm{S}$ & $\mathrm{T}$ & $\mathrm{Y}$ & Total \\
\hline $1 \mathrm{a}(\mathrm{CA})$ & $\begin{array}{c}290 \\
(78 \%)\end{array}$ & $\begin{array}{c}9 \\
(2 \%)\end{array}$ & $\begin{array}{c}13 \\
(3 \%)\end{array}$ & 1 & $\begin{array}{c}5 \\
(1 \%)\end{array}$ & $\begin{array}{c}28 \\
(8 \%)\end{array}$ & $\begin{array}{c}21 \\
(6 \%)\end{array}$ & $\begin{array}{c}6 \\
(2 \%)\end{array}$ & 373 \\
\hline $1 \mathrm{~b}(\mathrm{EP})$ & $\begin{array}{c}166 \\
(83 \%)\end{array}$ & $\begin{array}{c}4 \\
(2 \%)\end{array}$ & $\begin{array}{c}8 \\
(4 \%)\end{array}$ & $\begin{array}{c}3 \\
(1 \%)\end{array}$ & $\begin{array}{c}4 \\
(2 \%)\end{array}$ & $\begin{array}{c}13 \\
(6 \%)\end{array}$ & $\begin{array}{c}2 \\
(1 \%)\end{array}$ & 1 & 201 \\
\hline $1 \mathrm{c}(\mathrm{SF})$ & 0 & $-{ }^{\mathrm{a}}$ & $-^{\mathrm{a}}$ & $\begin{array}{c}6 \\
(5 \%)\end{array}$ & $\begin{array}{c}53 \\
(46 \%)\end{array}$ & $\begin{array}{c}7 \\
(6 \%)\end{array}$ & $\begin{array}{c}2 \\
(2 \%)\end{array}$ & $\begin{array}{c}46 \\
(40 \%)\end{array}$ & 114 \\
\hline 1d(TE) & 0 & $-{ }^{\mathrm{a}}$ & $-^{\mathrm{a}}$ & 0 & $\begin{array}{c}100 \\
(82 \%)\end{array}$ & $\begin{array}{c}15 \\
(12 \%)\end{array}$ & $\begin{array}{c}6 \\
(5 \%)\end{array}$ & 1 & 122 \\
\hline 1e(TZ) & 0 & $-^{\mathrm{a}}$ & $-{ }^{\mathrm{a}}$ & $\begin{array}{c}2 \\
(3 \%)\end{array}$ & $\begin{array}{c}70 \\
(90 \%)\end{array}$ & $\begin{array}{c}1 \\
(1 \%)\end{array}$ & $\begin{array}{c}3 \\
(4 \%)\end{array}$ & $\begin{array}{c}2 \\
(3 \%)\end{array}$ & 78 \\
\hline
\end{tabular}

C, cysteine; K, lysine; S, serine; Y, tyrosine; D, aspartic acid; H, histidine; T, threonine; E, glutamic acid.

${ }^{\mathrm{a}}$ The LC-MS/MS data obtained from the samples labeled with $\mathbf{1 c}(\mathrm{SF}), \mathbf{1 d}(\mathrm{TE})$ and $1 \mathrm{e}(\mathrm{TZ})$ were searched for C, K, S, Y, H and T (without D and E) as dynamic modification. 
Table S2. Classification of Et4-Rhod-labeled proteins in HeLa cells by cellular location using the protein ontology information provided in the UniProt database.

\begin{tabular}{c|ccccc}
\hline MRMs & Mitochondrial & $\begin{array}{c}\text { Other } \\
\text { organellar }\end{array}$ & Un-assigned & Total & $\begin{array}{c}\text { Ratio of } \\
\text { mitochondrial } \\
\text { proteins }\end{array}$ \\
\hline $\mathbf{1 a}(\mathrm{CA})$ & 196 & 38 & 10 & 244 & $80 \%$ \\
$\mathbf{1 b}(\mathrm{EP})$ & 85 & 35 & 11 & 131 & $65 \%$ \\
$\mathbf{1 c}(\mathrm{SF})$ & 53 & 21 & 0 & 74 & $72 \%$ \\
$\mathbf{1 d}(\mathrm{TE})$ & 52 & 9 & 4 & 65 & $80 \%$ \\
$\mathbf{1 e}(\mathrm{TZ})$ & 25 & 28 & 4 & 57 & $44 \%$ \\
Total & 259 & 95 & 21 & 375 & $69 \%$ \\
\hline
\end{tabular}


Table S3. The number of uniquely (or in overlap) labeled mitochondrial proteins in HeLa cells by each MRM.

\begin{tabular}{c|ccccc}
\hline & $\mathbf{1 a}(\mathrm{CA})$ & $\mathbf{1 b}(\mathrm{EP})$ & $\mathbf{1 c}(\mathrm{SF})$ & $\mathbf{1 d}(\mathrm{TE})$ & $\mathbf{1 e}(\mathrm{TZ})$ \\
\hline Unique & 105 & 10 & 18 & 14 & 4 \\
Overlapped & 91 & 75 & 35 & 38 & 21 \\
Total & 196 & 85 & 53 & 52 & 25 \\
\hline
\end{tabular}


Table S4. The number (and ratio) of Et4-Rhod-labeled residues of identified peptides in cortical cultured neurons

\begin{tabular}{|c|c|c|c|c|c|c|c|c|c|}
\hline MRMs & $\mathrm{C}$ & $\mathrm{D}$ & $\mathrm{E}$ & $\mathrm{H}$ & $\mathrm{K}$ & $\mathrm{S}$ & $\mathrm{T}$ & $\mathrm{Y}$ & Total \\
\hline $\mathbf{1 a}(\mathbf{C A})$ & $\begin{array}{c}132 \\
(71 \%)\end{array}$ & $\begin{array}{c}12 \\
(6 \%)\end{array}$ & $\begin{array}{c}11 \\
(6 \%)\end{array}$ & 0 & $\begin{array}{c}5 \\
(3 \%)\end{array}$ & $\begin{array}{c}14 \\
(8 \%)\end{array}$ & $\begin{array}{c}8 \\
(4 \%)\end{array}$ & $\begin{array}{c}3 \\
(2 \%)\end{array}$ & 185 \\
\hline $\mathbf{1 b}(\mathbf{E P})$ & $\begin{array}{c}36 \\
(82 \%)\end{array}$ & $\begin{array}{c}2 \\
(5 \%)\end{array}$ & 0 & $\begin{array}{c}2 \\
(5 \%)\end{array}$ & $\begin{array}{c}2 \\
(5 \%)\end{array}$ & $\begin{array}{c}1 \\
(2 \%)\end{array}$ & $\begin{array}{c}1 \\
(2 \%)\end{array}$ & 0 & 44 \\
\hline $\mathbf{1 c ( S F )}$ & 0 & $-{ }^{\mathrm{a}}$ & $-{ }^{\mathrm{a}}$ & $\begin{array}{c}4 \\
(6 \%)\end{array}$ & $\begin{array}{c}25 \\
(40 \%)\end{array}$ & $\begin{array}{c}5 \\
(8 \%)\end{array}$ & $\begin{array}{c}5 \\
(8 \%)\end{array}$ & $\begin{array}{c}24 \\
(38 \%)\end{array}$ & 63 \\
\hline $\mathbf{1 d}(\mathbf{T E})$ & $\begin{array}{c}2 \\
(3 \%)\end{array}$ & $-{ }^{\mathrm{a}}$ & $-{ }^{\mathrm{a}}$ & 0 & $\begin{array}{c}44 \\
(72 \%)\end{array}$ & $\begin{array}{c}11 \\
(18 \%)\end{array}$ & $\begin{array}{c}4 \\
(7 \%)\end{array}$ & 0 & 61 \\
\hline $\mathbf{1 e ( T Z )}$ & 0 & $-{ }^{\mathrm{a}}$ & $-{ }^{\mathrm{a}}$ & $\begin{array}{c}1 \\
(1 \%)\end{array}$ & $\begin{array}{c}62 \\
(82 \%)\end{array}$ & $\begin{array}{c}3 \\
(4 \%)\end{array}$ & $\begin{array}{c}6 \\
(8 \%)\end{array}$ & $\begin{array}{c}4 \\
(5 \%)\end{array}$ & 76 \\
\hline
\end{tabular}

${ }^{a}$ The LC-MS/MS data obtained from the samples labeled with $1 \mathbf{c}(\mathrm{SF}), \mathbf{1 d}(\mathrm{TE})$ and $1 \mathbf{e}(\mathrm{TZ})$ were searched for $\mathrm{C}, \mathrm{K}, \mathrm{S}, \mathrm{Y}, \mathrm{H}$ and $\mathrm{T}$ (without $\mathrm{D}$ and $\mathrm{E}$ ) as dynamic modification. 
Table S5. Classification of Et4-Rhod-labeled proteins in cortical cultured neurons by cellular location using the protein ontology information provided in the UniProt database

\begin{tabular}{c|ccccc}
\hline MRMs & Mitochondrial & $\begin{array}{c}\text { Other } \\
\text { organellar }\end{array}$ & Un-assignable & Total & $\begin{array}{c}\text { Ratio of } \\
\text { mitochondrial } \\
\text { proteins }\end{array}$ \\
\hline $\mathbf{1 a}(\mathrm{CA})$ & 84 & 39 & 11 & 134 & $63 \%$ \\
$\mathbf{1 b}(\mathrm{EP})$ & 25 & 13 & 2 & 40 & $63 \%$ \\
$\mathbf{1 c}(\mathrm{SF})$ & 34 & 7 & 0 & 41 & $83 \%$ \\
$\mathbf{1 d}(\mathrm{TE})$ & 32 & 15 & 0 & 47 & $68 \%$ \\
$\mathbf{1 e}(\mathrm{TZ})$ & 40 & 18 & 0 & 58 & $69 \%$ \\
Total & 129 & 72 & 11 & 212 & $61 \%$ \\
\hline
\end{tabular}


Table S6. Classification of Et4-Rhod-labeled proteins in brain slices by cellular location using the protein ontology information provided in the UniProt database

\begin{tabular}{c|ccccc}
\hline MRMs & Mitochondrial & $\begin{array}{c}\text { Other } \\
\text { organellar }\end{array}$ & Un-assignable & Total & $\begin{array}{c}\text { Ratio of } \\
\text { mitochondrial } \\
\text { proteins }\end{array}$ \\
\hline $\mathbf{1 a}(\mathrm{CA})$ & 78 & 35 & 11 & 124 & $63 \%$ \\
$\mathbf{1 b}(\mathrm{EP})$ & 10 & 3 & 0 & 13 & $77 \%$ \\
$\mathbf{1 c}(\mathrm{SF})$ & 22 & 5 & 0 & 27 & $81 \%$ \\
$\mathbf{1 d}(\mathrm{TE})$ & 13 & 2 & 1 & 16 & $81 \%$ \\
$\mathbf{1 e}(\mathrm{TZ})$ & 9 & 4 & 1 & 14 & $64 \%$ \\
Total & 100 & 45 & 11 & 156 & $64 \%$ \\
\hline
\end{tabular}


Table S7. The number (and ratio) of Et4-Rhod-labeled residues of identified peptides in brain slices

\begin{tabular}{|c|c|c|c|c|c|c|c|c|c|}
\hline MRMs & $\mathrm{C}$ & $\mathrm{D}$ & $\mathrm{E}$ & $\mathrm{H}$ & $\mathrm{K}$ & $\mathrm{S}$ & $\mathrm{T}$ & $\mathrm{Y}$ & Total \\
\hline $\mathbf{1 a}(\mathrm{CA})$ & $\begin{array}{c}114 \\
(75 \%)\end{array}$ & $\begin{array}{c}7 \\
(5 \%)\end{array}$ & $\begin{array}{c}6 \\
(4 \%)\end{array}$ & $\begin{array}{c}2 \\
(1 \%)\end{array}$ & $\begin{array}{c}6 \\
(4 \%)\end{array}$ & $\begin{array}{c}11 \\
(7 \%)\end{array}$ & $\begin{array}{c}7 \\
(5 \%)\end{array}$ & 0 & 153 \\
\hline $\mathbf{1 b}(\mathrm{EP})$ & $\begin{array}{c}15 \\
(88 \%)\end{array}$ & 0 & 0 & 0 & 0 & $\begin{array}{c}2 \\
(22 \%)\end{array}$ & 0 & 0 & 17 \\
\hline $\mathbf{1 c}(\mathrm{SF})$ & 0 & $-^{\mathrm{a}}$ & $-^{\mathrm{a}}$ & $\begin{array}{c}2 \\
(7 \%)\end{array}$ & $\begin{array}{c}8 \\
(30 \%)\end{array}$ & $\begin{array}{c}2 \\
(7 \%)\end{array}$ & $\begin{array}{c}1 \\
(4 \%)\end{array}$ & $\begin{array}{c}14 \\
(52 \%)\end{array}$ & 27 \\
\hline $\mathbf{1 d}(\mathrm{TE})$ & 0 & $--^{\mathrm{a}}$ & $-{ }^{\mathrm{a}}$ & 0 & $\begin{array}{c}11 \\
(69 \%)\end{array}$ & $\begin{array}{c}4 \\
(25 \%)\end{array}$ & $\begin{array}{c}1 \\
(6 \%)\end{array}$ & 0 & 16 \\
\hline $\mathbf{1 e}(\mathrm{TZ})$ & 0 & $-^{\mathrm{a}}$ & $-{ }^{\mathrm{a}}$ & $\begin{array}{c}1 \\
(5 \%)\end{array}$ & $\begin{array}{c}15 \\
(79 \%)\end{array}$ & $\begin{array}{c}1 \\
(5 \%)\end{array}$ & $\begin{array}{c}1 \\
(5 \%)\end{array}$ & $\begin{array}{c}1 \\
(5 \%)\end{array}$ & 19 \\
\hline
\end{tabular}

${ }^{\mathrm{a}}$ The LC-MS/MS data obtained from the samples labeled with $\mathbf{1 c}(\mathrm{SF}), \mathbf{1 d}(\mathrm{TE})$ and $\mathbf{1 e}(\mathrm{TZ})$ were searched for C, K, S, Y, H and T (without D and E) as dynamic modification. 
Table S8. List of significantly up-regulated proteins with $>2$-fold change during PQ-induced apoptosis

$\log _{2} \mathrm{PQ} /$ Control

\begin{tabular}{|c|c|c|c|c|c|}
\hline Protein (Gene) & Ex.1 & Ex.2 & Ex.3 & average & mitochondria \\
\hline $\begin{array}{l}\text { Apoptosis-inducing factor } 1 \text {, mitochondrial } \\
\text { (AIFM1) }\end{array}$ & 2.09 & 3.01 & - & 2.55 & Yes \\
\hline $\begin{array}{l}\text { Aconitate hydratase, mitochondrial } \\
(\mathrm{ACO} 2)\end{array}$ & 2.50 & 2.51 & 2.62 & 2.54 & Yes \\
\hline MICOS complex subunit MIC60 (IMMT) & 2.56 & 2.48 & - & 2.52 & Yes \\
\hline Alpha-actinin-1 (ACTN1) & - & 1.25 & 3.17 & 2.21 & No \\
\hline Desmoplakin (DSP) & - & 1.00 & 2.76 & 1.88 & Yes \\
\hline Actin, cytoplasmic 1 (ACTB) & 0.83 & 1.93 & 2.71 & 1.82 & No \\
\hline $\begin{array}{l}\text { Glyceraldehyde-3-phosphate } \\
\text { dehydrogenase (GAPDH) }\end{array}$ & 0.47 & 2.44 & 2.53 & 1.81 & Yes \\
\hline Myosin-9 (MYH9) & - & 1.49 & 2.13 & 1.81 & No \\
\hline Actin, alpha cardiac muscle 1 (ACTC1) & 0.87 & 1.52 & 2.88 & 1.76 & No \\
\hline Histone H2B type 1-K (HIST1H2BK) & - & 0.61 & 3.91 & 1.65 & No \\
\hline Peroxiredoxin-2 (PRDX2) & 1.50 & 1.46 & - & 1.48 & Yes \\
\hline $\begin{array}{l}60 \mathrm{kDa} \text { heat shock protein, mitochondrial } \\
\text { (HSPD1) }\end{array}$ & 1.06 & 1.36 & 1.91 & 1.45 & Yes \\
\hline Glutathione peroxidase 1 (GPX1) & - & 1.24 & 1.49 & 1.36 & Yes \\
\hline $\begin{array}{l}\text { Solute carrier family } 2 \text {, facilitated glucose } \\
\text { transporter member } 1 \text { (SLC2A } 1 \text { ) }\end{array}$ & 1.20 & 1.35 & 1.48 & 1.35 & No \\
\hline $\begin{array}{l}\text { Peptidyl-prolyl cis-trans isomerase A } \\
\text { (PPIA) }\end{array}$ & - & 0.87 & 1.76 & 1.32 & No \\
\hline Peroxiredoxin-1 (PRDX1) & 1.29 & 0.93 & 1.47 & 1.23 & Yes \\
\hline $\begin{array}{l}\text { Superoxide dismutase }[\mathrm{Mn}], \text { mitochondrial } \\
\text { (SOD2) }\end{array}$ & 0.96 & 1.05 & 1.33 & 1.11 & Yes \\
\hline $\begin{array}{l}\text { Dihydrolipoyl dehydrogenase, } \\
\text { mitochondrial (DLD) }\end{array}$ & 1.00 & 1.11 & - & 1.05 & Yes \\
\hline Importin subunit beta-1 (KPNB1) & - & 0.69 & 1.40 & 1.04 & No \\
\hline $\begin{array}{l}\text { Mitochondrial glutamate carrier } 2 \\
\text { (SLC25A18) }\end{array}$ & 1.68 & - & 0.40 & 1.04 & Yes \\
\hline 40S ribosomal protein S16 (RPS16) & - & 0.62 & 1.42 & 1.02 & No \\
\hline
\end{tabular}


Table S9. List of significantly down-regulated proteins with $>2$-fold change during PQ-induced apoptosis

$\log _{2} \mathrm{PQ} /$ Control

\begin{tabular}{|c|c|c|c|c|c|}
\hline Protein (Gene) & Ex.1 & Ex.2 & Ex.3 & average & mitochondria \\
\hline $\begin{array}{l}\text { NADH dehydrogenase [ubiquinone] } \\
\text { alpha subcomplex assembly factor } \\
\text { (NDUFAF4) }\end{array}$ & -1.96 & -2.39 & -2.50 & -2.28 & Yes \\
\hline Kinesin-like protein KIF23 (KIF23) & -1.60 & -1.66 & -2.00 & -1.75 & No \\
\hline $\begin{array}{l}\text { NADH dehydrogenase } \\
\text { iron-sulfur protein } 3, \text { mitochondrial } \\
\text { (NDUFS3) }\end{array}$ & -1.10 & - & -2.05 & -1.58 & Yes \\
\hline $\begin{array}{l}\text { Mitochondrial intermediate peptidase } \\
\text { (MIPEP) }\end{array}$ & -1.46 & -1.56 & -1.72 & -1.58 & Yes \\
\hline $\begin{array}{l}\text { NADH-ubiquinone oxidoreductase } 75 \mathrm{kDa} \\
\text { subunit, mitochondrial (NDUFS1) }\end{array}$ & - & -1.24 & -1.51 & -1.37 & Yes \\
\hline Ferritin heavy chain (FTH1) & -1.02 & -1.43 & -0.94 & -1.13 & Yes \\
\hline Fatty acid synthase (FASN) & -0.63 & -1.73 & -1.02 & -1.13 & Yes \\
\hline $\begin{array}{l}\text { Acyl-CoA dehydrogenase family member } \\
9, \text { mitochondrial (ACAD9) }\end{array}$ & -1.19 & -1.07 & -0.97 & -1.08 & Yes \\
\hline
\end{tabular}




\section{General materials and methods for the biochemical/biological experiments.}

Unless otherwise noted, all proteins/enzymes and reagents were obtained from commercial suppliers (Sigma-Aldrich, Tokyo Chemical Industry (TCI), Wako Pure Chemical Industries, Sasaki Chemical, Bio-Rad, or Watanabe Chemical Industries) and used without further purification. UV-vis absorption spectra were acquired on a Shimazu UV-2550 spectrophotometer. SDS-polyacrylamide gel electrophoresis (SDS-PAGE) and western blotting were carried out using a Bio-Rad Mini-Protean III electrophoresis apparatus. Fluorescence gel images and chemical luminescent signals using Chemi-Lumi one (Nacalai Tesque) or ECL Prime (GE Healthcare) were acquired with an imagequant LAS4000 (GE Healthcare). Cell imaging was performed with a confocal laser scanning microscope (CLSM, Olympus, FV10i) using 60x objectives, and images were analyzed using accompanying FV10i-ASW 3.0 Viewer software.

\section{Preparation of anti-Et4-Rhod antiserum}

To a stirred solution of 1-2 $(9.0 \mathrm{mg}, 14 \mu \mathrm{mol})$ in dry $N, N$-dimethylformamide (DMF, $0.4 \mathrm{~mL})$ was added 1-ethyl-3-(3-dimethylaminopropyl)carbodiimide hydrochloride (EDCI-HCl) (3.0 $\mathrm{mg}, 16 \mu \mathrm{mol}$ ) and sulfo-NHS (Thermo, $3.9 \mathrm{mg}, 18 \mu \mathrm{mol}$ ) at room temperature. The solution was allowed to stir for $4 \mathrm{~h}$. After removing the solvent in vacuo, a solution of bovine serum albumin (BSA, $20 \mathrm{mg}$ ) in phosphate-buffered saline (PBS, $2 \mathrm{~mL}$ ) was added to the residue at room temperature. The protein solution was stirred for $30 \mathrm{~min}$. To remove excess amount of coupling reagents, the BSA solution was dialyzed against PBS at $4{ }^{\circ} \mathrm{C}$. Rabbit anti-Et4-Rhod antiserum was produced by Sigma-Aldrich Japan Custom Antibody service via immunizing a rabbit with the Et4-Rhod-BSA conjugate. In this study, we used the serum fraction without any purification.

\section{Evaluation of the performance of the anti-Et4-Rhod antibody}

Bovine carbonic anhydrase (Worthington biochemical corporation, bCA, $173 \mu \mathrm{M}$ ) was incubated with 1d (TE) $(500 \mu \mathrm{M})$ in PBS at $37{ }^{\circ} \mathrm{C}$. After $2 \mathrm{~h}$, the Et4-Rhod-modified bCA 
was purified by size-exclusion chromatography using PD-10 column (GE healthcare). The modification yield was determined as $\sim 50 \%$ by the absorbance at $567 \mathrm{~nm}$ and $280 \mathrm{~nm}$ using the molar absorption coefficient of Et4-Rhod $\left(\varepsilon_{567 \mathrm{~nm}}=96,100 \mathrm{~cm}^{-1} \mathrm{M}^{-1}\right.$ (Ref. S1), $\varepsilon_{280 \mathrm{~nm}}=$ $16,100 \mathrm{~cm}^{-1} \mathrm{M}^{-1}$ (Ref. S5)) and bCA $\left(\varepsilon_{280 \mathrm{~nm}}=50,070 \mathrm{~cm}^{-1} \mathrm{M}^{-1}\right.$, theoretical). To examine the detection sensitivity and selectivity, 2, 10, 20, 200 fmol of the Et4-Rhod-modified bCA were mixed with $8 \mu \mathrm{g}$ of protein extract from HeLa cells lysate, and analyzed by western blotting with the anti-Et4-Rhod antibody (antiserum) (1:1000 dilution), followed by goat anti-rabbit IgG-HRP (Santa Cruz, SC-2004, 1:3000 dilution).

To evaluate the efficiency of the anti-Et4-Rhod antibody for enriching the labeled proteins, the Et4-Rhod-modified bCA $(1 \mu \mathrm{M})$ in $100 \mu \mathrm{L}$ of RIPA buffer $(25 \mathrm{mM}$ Tris, $150 \mathrm{mM} \mathrm{NaCl}$, $0.1 \%$ Sodium dodecyl sulfate, $1 \%$ Nonidet P-40, $1 \%$ sodium deoxycholate, $\mathrm{pH} 7.6$ ) was gently vortexed with $2.0 \mu \mathrm{L}$ of anti-Et4-Rhod antibody for $1 \mathrm{~h}$ at room temperature, followed by addition of $20 \mu \mathrm{L}$ of nProtein A sepharose 4 Fast Flow (GE Healthcare) and further vortexed for $1 \mathrm{~h}$. The beads were washed with RIPA buffer $(1 \mathrm{~mL} \times 5)$ and PBS $(1 \mathrm{~mL} \times 5)$, and boiled in $20 \mu \mathrm{L}$ of $2 \times$ SDS-PAGE loading buffer (pH 6.8, $130 \mathrm{mM}$ Tris, $8 \%$ sucrose, $6 \%$ SDS, $0.012 \%$ bromophenol blue) containing $250 \mathrm{mM}$ DTT. The samples were resolved by SDS-PAGE, and the Et4-Rhod labeled proteins were visualized fluorescence gel imager (LAS4000, GE Healthcare).

\section{Preparation of primary cortical neuronal culture}

Cerebral cortices from 16-d-old Sprague Dawley rat embryos were aseptically dissociated and digested with $0.25 \mathrm{w} / \mathrm{v} \%$ trypsin (Nacalai tesque) for $20 \mathrm{~min}$. After centrifugation, the cells were re-suspended in Neurobasal medium supplemented with $2 \%$ NS2 1 supplement, ${ }^{\mathrm{S} 6} 0.5$ $\mathrm{mM}$ glutamine (Invitrogen), penicillin (100 units/ml) and streptomycin $(100 \mu \mathrm{g} / \mathrm{ml})$, and were plated $1.5 \times 10^{4}$ cells on $35 \mathrm{~mm}$ glass based dishes (Mastunami) or $6 \times 10^{5}$ cells on 12 -well plate (BD Falcon) coated with poly-D-lysine (Sigma-Aldrich), and maintained at $37{ }^{\circ} \mathrm{C}$ in a humidified atmosphere of $95 \%$ air and $5 \% \mathrm{CO}_{2}$. The cultured medium was exchanges every 3 days, and the neurons were used for the labeling experiments at 10 days in vitro (DIV). 


\section{Mitochondrial proteome labeling and CLSM analyses in cortical neurons}

Cultured neural cells were washed twice with serum-free DMEM, and incubated in serum free DMEM containing MRM $(1-5 \mu \mathrm{M})$ for $2-6 \mathrm{~h}$. The intracellular localization of these reagents was analyzed by CLSM. After labeling reaction, the cells were washed twice with chilled PBS, and lysed by sonication in modified-RIPA buffer containing 1\% Protease Inhibitor Cocktail at $4{ }^{\circ} \mathrm{C}$. The solubilized proteins were normalized for protein concentration, and SDS-PAGE analysis was performed as described in the method section in the main text.

\section{Mitochondrial proteome labeling of acutely prepared brain slices}

Brain slices (cerebrum, $250 \mu \mathrm{m}$ thickness) were prepared from P14-21 ICR mice. The slices were incubated in ACSF solution (125 mM NaCl, $2.5 \mathrm{mM} \mathrm{KCl}, 2 \mathrm{mM} \mathrm{CaCl} 2,1 \mathrm{mM} \mathrm{MgCl}_{2}$, $1.25 \mathrm{mM} \mathrm{NaH}_{2} \mathrm{PO}_{4}, 26 \mathrm{mM} \mathrm{NaHCO}_{3}$ and $10 \mathrm{mM}$ D-glucose) containing 5.0-15 $\mu \mathrm{M}$ of MRM at room temperature for $2-6 \mathrm{~h}$ under $95 \% \mathrm{O}_{2} / 5 \% \mathrm{CO}_{2}$. The slices were then washed with PBS twice and lysed by sonication in modified-RIPA buffer containing $1 \%$ Protease Inhibitor Cocktail at $4{ }^{\circ} \mathrm{C}$. The solubilized proteins were normalized for protein concentration, and SDS-PAGE analysis was performed as described in the method section in the main text.

\section{Determination of intracellular concentration of MRMs in HeLa cell.}

HeLa cells $\left(1.0 \times 10^{7}\right.$ cells $)$ were incubated in serum-free DMEM containing MRM (1a-1c: $10 \mu \mathrm{M}$ for $6 \mathrm{~h}, \mathbf{1 d}$ and $\mathbf{1 e}: 5 \mu \mathrm{M}$ for $2 \mathrm{~h}$, $\mathbf{1 f}: 5 \mu \mathrm{M}$ for $30 \mathrm{~min}, \mathbf{1 g}$ : $10 \mu \mathrm{M}$ for $30 \mathrm{~min}$ ). The cells were washed twice with chilled PBS and harvested from cultures using trypsin solution. After washing twice with PBS buffer, the cell number was adjusted to $1.0 \times 10^{7}$ cells, and the cells were lysed by sonication in modified-RIPA buffer $(300 \mu \mathrm{L})$. The lysate was centrifuged at $16000 \times \mathrm{g}$ for $3 \mathrm{~min}$, and the supernatant was collected. The volume of the lysate was adjusted to $500 \mu \mathrm{L}$, and the concentration of Et4-Rhod in cell lysate was determined by UV-vis absorption spectra using the molar absorption coefficient of $96,100 \mathrm{~cm}^{-1} \mathrm{M}^{-1}$ (Ref. S1). 
Finally, the averaged intracellular concentration of each MRM in a single cell was determined from the cell number and a typical single cell volume ${ }^{\mathrm{S} 7}$ (HeLa cell volume was reported as $2.4 \mathrm{pL})$.

\section{Protein labeling in cell lysate}

HeLa cell lysates were prepared by using modified-RIPA buffer, brought up to the protein concentration of $3.0 \mathrm{mg} / \mathrm{mL}$, and incubated with $10 \mu \mathrm{M}$ of $1 \mathrm{a}(\mathrm{CA})$ at $37^{\circ} \mathrm{C}$ for $6 \mathrm{~h}$. LC-MS samples were prepared as described above (in-solution digested sample, method A).

\section{Protein labeling in CCCP-pretreated cells}

HeLa cells $\left(1.0 \times 10^{6}\right.$ cells $)$ were cultured on $10 \mathrm{~cm}$ dishes at $37{ }^{\circ} \mathrm{C}$ for $48 \mathrm{~h}$ in DMEM supplemented with $10 \%$ FBS and 1\% Anti-Anti. The cells were washed twice with serum-free DMEM and preincubated with $5.0 \mu \mathrm{M}$ of CCCP for $5 \mathrm{~min}$ before protein labeling. After the incubation, the uncoupled cells were incubated with $10 \mu \mathrm{M}$ of $1 \mathrm{a}(\mathrm{CA})$ at $37{ }^{\circ} \mathrm{C}$ for $6 \mathrm{~h}$. LC-MS samples were prepared as described above (in-solution digested sample, method A).

\section{Western blotting analyses in PQ-treated oxidative stress}

PQ-treated or non-treated cells were prepared as described above. The cells were washed twice with PBS, and lysed by sonication in modified-RIPA buffer containing $1 \%$ Protease Inhibitor Cocktail. The samples were resolved by SDS-PAGE (10 $\mu \mathrm{g}$ protein/lane). The proteins were electrotransferred onto immune-blot PVDF membranes, followed by blocking with 5\% non-fat dry milk in TBS containing $0.05 \%$ Tween. Antibodies used in this experiment are as follows: anti- $\beta$-Actin (Abcam, ab8226, mouse), anti-HADHA (Abcam, ab137831, rabbit), anti-ACO2 (Cell signaling technology, 6922S, rabbit), anti-GRP75 (HSPA9) (Cell signaling technology, 2816S, rabbit), anti-AIFM1 (Cell signaling technology, D39D2, rabbit), anti-FASN (Cell signaling technology, C20G5, rabbit), anti-NDUFS3 
(Abcam, ab110246, mouse), anti-NDUFAF4 (Abcam, ab191414, rabbit), anti-PARP-1 (Abcam, ab32138, rabbit), goat anti-rabbit IgG-HRP (Santa Cruz, SC-2004), goat anti-mouse IgG-HRP (Santa Cruz, SC-2005) or rabbit anti-goat IgG-HRP (Santa Cruz, SC-2768). 


\section{General materials and methods for organic synthesis}

All chemical reagents and solvents were obtained from commercial suppliers (Sigma-Aldrich, Tokyo Chemical Industry (TCI), Wako Pure Chemical Industries, Sasaki Chemical, or Watanabe Chemical Industries) and used without further purification.

All reactions were carried out under an atmosphere of nitrogen unless otherwise noted. Thin layer chromatography (TLC) was performed on silica gel 60 F254 precoated aluminium sheets (Merck) and visualized by fluorescence quenching or ninhydrin staining. Chromatographic purification was accomplished using flash column chromatography on silica gel $60 \mathrm{~N}$ (neutral, 40-50 $\mu \mathrm{m}$, Kanto Chemical). ${ }^{1} \mathrm{H}$ NMR spectra were recorded in deuterated solvents on a Varian Mercury $400(400 \mathrm{MHz})$ spectrometer and calibrated to the residual solvent peak or tetramethylsilane $(=0 \mathrm{ppm})$. Multiplicities are abbreviated as follows: $\mathrm{s}=$ singlet, $\mathrm{d}=$ doublet, $\mathrm{t}=$ triplet, $\mathrm{q}=$ quartet, $\mathrm{m}=$ multiplet, $\mathrm{dd}=$ double doublet. Matrix-assisted laser desorption/ionization time-of-flight mass spectrometry (MALDI-TOF MS) spectra were recorded on an Autoflex III instrument (Bruker Daltonics) using $\alpha$-cyano-4-hydroxycinnamic acid (CHCA) as the matrix. High-resolution mass spectra were measured on an Exactive (Thermo Scientific) equipped with electron spray ionization (ESI). Reversed-phase HPLC (RP-HPLC) was carried out on a Hitachi LaChrom L-7100 system equipped with a LaChrom L-7400 UV detector, and a YMC-Pack ODS-A column (5 $\mu \mathrm{m}, 250$ $\times 20 \mathrm{~mm}$ ) at a flow rate of $9.9 \mathrm{~mL} / \mathrm{min}$. UV detection was at $220 \mathrm{~nm}$. All runs used linear gradients of acetonitrile containing $0.1 \%$ TFA (solvent $\mathrm{A}$ ) and $0.1 \%$ aqueous TFA (solvent B). 


\section{Synthesis of MRMs}

Scheme S1. Synthetic scheme of MRMs.

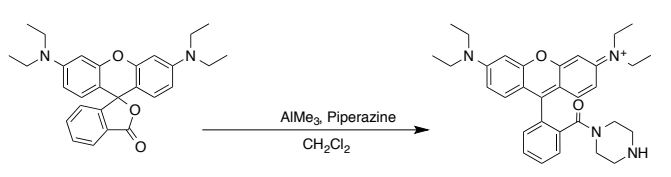

Rhodamine B base

1-1

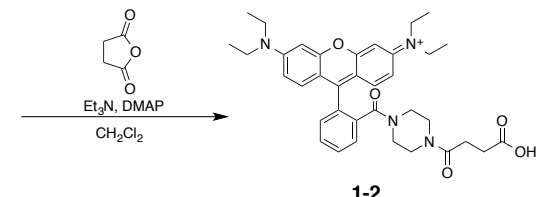

$1-2$
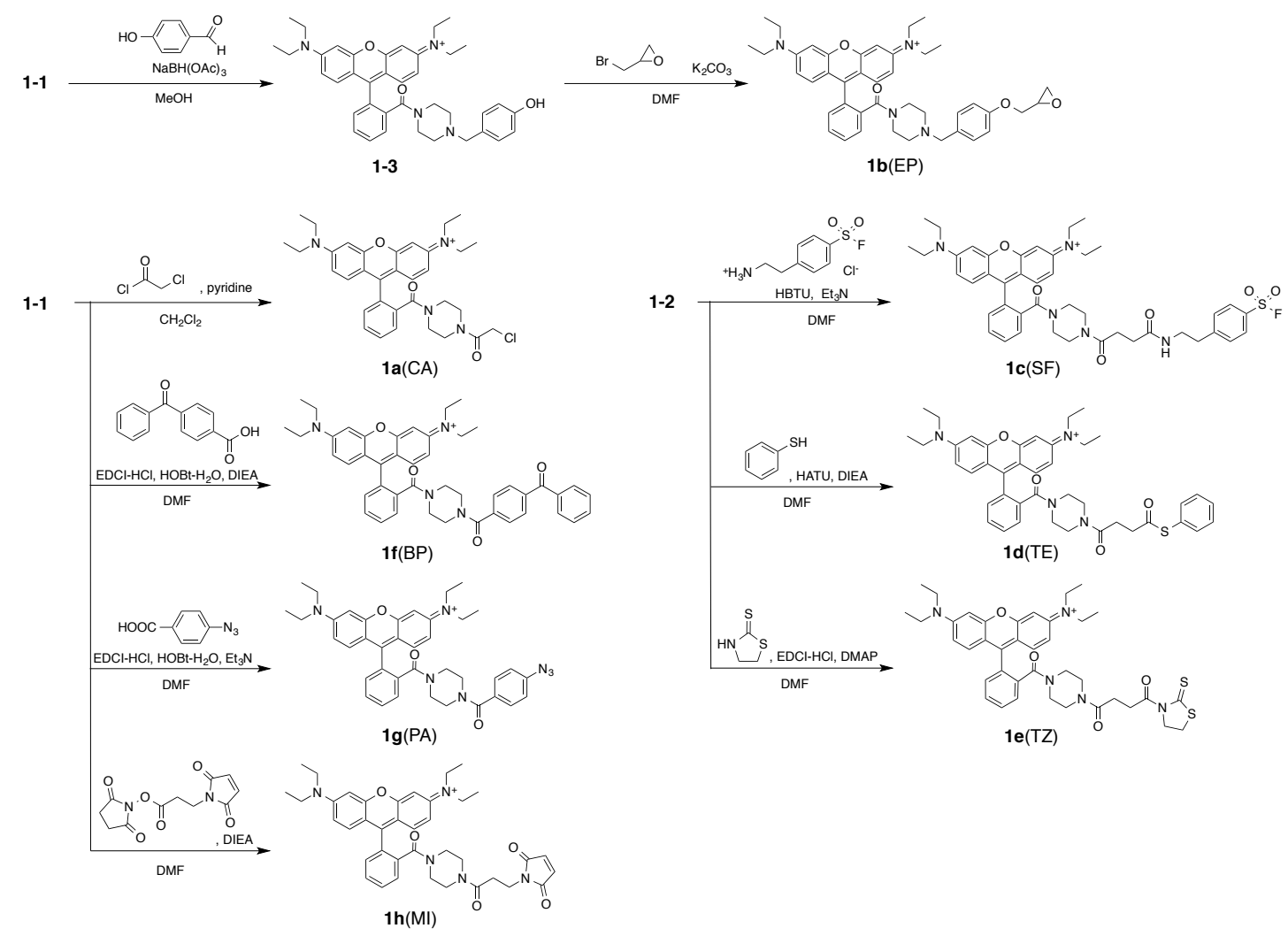

Synthesis of $\mathbf{1 - 1}^{\mathrm{S} 1}$

A 2.0 $\mathrm{M}$ solution of trimethyl aluminum in toluene $(11.3 \mathrm{~mL}, 22.6 \mathrm{mmol})$ was added dropwise to a solution of piperazine $(7.80 \mathrm{~g}, 91.0 \mathrm{mmol})$ in dry $\mathrm{CH}_{2} \mathrm{Cl}_{2}(18 \mathrm{~mL})$ at room temperature. A solution of rhodamine $\mathrm{B}$ base $(5.00 \mathrm{~g}, 11.3 \mathrm{mmol})$ in dry $\mathrm{CH}_{2} \mathrm{Cl}_{2}(10 \mathrm{~mL})$ was added dropwise to the heterogeneous solution. After stirring for $22 \mathrm{~h}$ at $50{ }^{\circ} \mathrm{C}, 0.1 \mathrm{M} \mathrm{HCl} \mathrm{aq}$ $(10 \mathrm{~mL})$ was added to the mixture at room temperature. The precipitate was filtered, and the 
retained solids were washed with $\mathrm{CH}_{2} \mathrm{Cl}_{2}$ and $\mathrm{CH}_{2} \mathrm{Cl}_{2}$ : $\mathrm{MeOH}(4: 1)$. The combined filtrate was partitioned between dilute aqueous $\mathrm{NaHCO}_{3}(0.02 \%, 200 \mathrm{~mL})$ and then the aqueous layer was washed with AcOEt $(10 \mathrm{~mL} \times 3,20 \mathrm{~mL} \times 2)$. The aqueous layer was saturated with $\mathrm{NaCl}$, acidified with $1 \mathrm{M}$ aqueous $\mathrm{HCl}$, and then extracted with multiple portions of $i-\mathrm{PrOH} / \mathrm{CH}_{2} \mathrm{Cl}_{2}$ $(4 / 1 \mathrm{v} / \mathrm{v})$. The combined organic layers were then dried over $\mathrm{Na}_{2} \mathrm{SO}_{4}$, filtered, and concentrated under reduced pressure. The dark purple solid was dissolved in $16 \mathrm{~mL}$ of $\mathrm{MeOH}$, and then precipitated by addition to $\mathrm{Et}_{2} \mathrm{O}(600 \mathrm{~mL})$. The precipitate was collected by filtration to yield 1-1 as a dark purple solid (4.33 g, 75\%). ${ }^{1} \mathrm{H}-\mathrm{NMR}\left(400 \mathrm{MHz}, \mathrm{CD}_{3} \mathrm{OD}\right): \delta 7.83-7.67$ $(\mathrm{m}, 3 \mathrm{H}), 7.57-7.51(\mathrm{~m}, 1 \mathrm{H}), 7.28(\mathrm{~d}, 2 \mathrm{H}, J=5.2 \mathrm{~Hz}), 7.10(\mathrm{dd}, 2 \mathrm{H}, J=9.6,2.8 \mathrm{~Hz}), 6.98(\mathrm{~d}$, $2 \mathrm{H}, J=3.4 \mathrm{~Hz}), 3.79-3.48(\mathrm{~m}, 12 \mathrm{H}), 3.12(\mathrm{~s}, 4 \mathrm{H}), 1.32(\mathrm{t}, 12 \mathrm{H}, J=6.8 \mathrm{~Hz})$.

\section{Synthesis of $1-\mathbf{2}^{\mathrm{S} 1}$}

To a stirred solution of 1-1 $(1.00 \mathrm{~g}, 1.83 \mathrm{mmol})$ in $\mathrm{CH}_{2} \mathrm{Cl}_{2}(6 \mathrm{~mL})$ was added $\mathrm{Et}_{3} \mathrm{~N}(0.25 \mathrm{~mL}$, $2.0 \mathrm{mmol})$, succinic anhydride $(0.20 \mathrm{~g}, 2.0 \mathrm{mmol})$ and 4-dimethylaminopyridine (DMAP) $(0.25 \mathrm{~g}, 2.1 \mathrm{mmol})$. The mixture was stirred for $14 \mathrm{~h}$ at room temperature. The resulting mixture was added to $25 \mathrm{~mL}$ of aqueous $1 \mathrm{M} \mathrm{K}_{2} \mathrm{CO}_{3}$. The aqueous layer was washed with AcOEt $(16 \mathrm{~mL} \times 7)$. The aqueous layer was saturated with $\mathrm{NaCl}$ then extracted with $i-\mathrm{PrOH} / \mathrm{CH}_{2} \mathrm{Cl}_{2}(4 / 1)(30 \mathrm{~mL} \times 3)$. The organic layer was dried over $\mathrm{Na}_{2} \mathrm{SO}_{4}$ and filtered. The filtrate was evaporated under reduced pressure. The residue was dissolved in $\mathrm{CHCl}_{3}(50 \mathrm{~mL})$ and filtered. The filtrate was evaporated to yield 1-2 as a dark purple solid (1.06 g, 90 \%). ${ }^{1} \mathrm{H}-\mathrm{NMR}\left(400 \mathrm{MHz}, \mathrm{CD}_{3} \mathrm{OD}\right): \delta 7.84-7.68(\mathrm{~m}, 3 \mathrm{H}), 7.56-7.48(\mathrm{~m}, 1 \mathrm{H}), 7.29(\mathrm{~d}, 2 \mathrm{H}, J=9.6$ Hz), 7.14-7.04 (m, 2H), 6.96 (d, 2H, $J=2.8 \mathrm{~Hz}), 3.69$ (q, 8H, $J=7.2 \mathrm{~Hz}), 3.53-3.32(\mathrm{~m}, 8 \mathrm{H})$, $2.55(\mathrm{t}, 2 \mathrm{H}, J=6.4 \mathrm{~Hz}), 2.40(\mathrm{t}, 2 \mathrm{H}, J=7.2 \mathrm{~Hz}), 1.31(\mathrm{t}, 12 \mathrm{H}, J=7.2 \mathrm{~Hz})$.

\section{Synthesis of 1-3}

To a stirred solution of 1-1 (78 $\mathrm{mg}, 0.14 \mathrm{mmol})$ in dry $\mathrm{MeOH}(5.0 \mathrm{~mL})$ was added 4-hydroxybenzaldehyde (72 $\mathrm{mg}, 0.59 \mathrm{mmol})$ at room temperature. After stirring for $1 \mathrm{~h}$, 
sodium triacetoxyborohydride $(152 \mathrm{mg}, 0.712 \mathrm{mmol})$ was added to the mixture, and stirred for $1.5 \mathrm{~h}$ at room temperature. After removing the solvent in vacuo, the residue was purified by flash column chromatography ( silica, $\mathrm{CHCl}_{3}: \mathrm{MeOH}=20: 1,1 \% \mathrm{NH}_{3}$ aq) to yield 1-3 as a dark purple solid (20 mg, 21\%). ${ }^{1} \mathrm{H}-\mathrm{NMR}\left(400 \mathrm{MHz}, \mathrm{CD}_{3} \mathrm{OD}\right): \delta 7.79-7.70(\mathrm{~m}, 2 \mathrm{H})$, 7.67-7.61(m, 1H), 7.56-7.48 (m, 1H), $7.28(\mathrm{~d}, 2 \mathrm{H}, J=9.6 \mathrm{~Hz}), 6.98-7.12(\mathrm{~m}, 6 \mathrm{H}), 6.69(\mathrm{~d}$, $2 \mathrm{H}, J=2.0 \mathrm{~Hz}), 3.79-3.60(\mathrm{~m}, 8 \mathrm{H}), 3.42-3.23(\mathrm{~m}, 6 \mathrm{H}), 2.30-1.99(\mathrm{~m}, 4 \mathrm{H}), 1.33(\mathrm{t}, 12 \mathrm{H}, J=$ $7.2 \mathrm{~Hz})$.

Synthesis of $1 \mathbf{a}(\mathrm{CA})^{\mathrm{S} 1}$

To a stirred solution of 1-1 (100 mg, $0.128 \mathrm{mmol})$ and pyridine $(35 \mu \mathrm{L}, 0.44 \mathrm{mmol})$ in dry $\mathrm{CH}_{2} \mathrm{Cl}_{2}(1.0 \mathrm{~mL})$ was slowly added dropwise chloroacetyl chloride $(30 \mu \mathrm{L}, 0.44 \mathrm{mmol})$ at 0 ${ }^{\circ} \mathrm{C}$. After stirring for $4 \mathrm{~h}$, additional chloroacetyl chloride $(100 \mu \mathrm{L}, 1.46 \mathrm{mmol})$ and pyridine (50 $\mu \mathrm{L}, 0.62 \mathrm{mmol}$ ) was added to the mixture. The reaction solution was warmed to room temperature and allowed to stir for $4 \mathrm{~h}$. The solution was concentrated under reduced pressure and partitioned between $\mathrm{Et}_{2} \mathrm{O}$ and $50 \mathrm{~mL}$ of aqueous $1 \mathrm{M} \mathrm{K}_{2} \mathrm{CO}_{3}$. After washing with three portions of $\mathrm{Et}_{2} \mathrm{O}(30 \mathrm{~mL})$, the aqueous layer was extracted with three portions of $i$ - $\mathrm{PrOH} / \mathrm{CH}_{2} \mathrm{Cl}_{2}$ (1/4). The combined organic layer was dried over $\mathrm{Na}_{2} \mathrm{SO}_{4}$, filtered and evaporated. The crude product was purified by flash column chromatography (silica, $\mathrm{CH}_{2} \mathrm{Cl}_{2}$ : $\mathrm{MeOH}=10: 1$ to $10: 3)$ to yield $\mathbf{1 a}(\mathrm{CA})$ as a dark purple solid (36 mg, 31\%). ${ }^{1} \mathrm{H}-\mathrm{NMR}(400$ $\left.\mathrm{MHz}, \mathrm{CD}_{3} \mathrm{OD}\right): \delta 7.81-7.75(\mathrm{~m}, 2 \mathrm{H}), 7.73-7.69(\mathrm{~m}, 1 \mathrm{H}), 7.54-7.50(\mathrm{~m}, 1 \mathrm{H}), 7.29(\mathrm{~d}, 2 \mathrm{H}, J=$ $9.6 \mathrm{~Hz}), 7.09-7.05(\mathrm{~m}, 2 \mathrm{H}), 6.97(\mathrm{~d}, 2 \mathrm{H}, J=2.0 \mathrm{~Hz}), 4.20$ (s, 2H), 3.69 (q, 8H, $J=7.2 \mathrm{~Hz})$, 3.35-3.17 (m, 8H), $1.31(\mathrm{t}, 12 \mathrm{H}, J=6.8 \mathrm{~Hz})$. HRMS (ESI): Calcd for $\left(\mathrm{C}_{34} \mathrm{H}_{40} \mathrm{ClN}_{4} \mathrm{O}_{3}\right)^{+}$ 587.2783. Found: 587.2776.

\section{Synthesis of $\mathbf{1 b}(\mathrm{EP})$}

To a stirred solution of $\mathbf{1 - 3}(15 \mathrm{mg}, 23 \mu \mathrm{mol})$ in dry DMF $(2.0 \mathrm{~mL})$ was added $\mathrm{K}_{2} \mathrm{CO}_{3}(12 \mathrm{mg}$, $89 \mu \mathrm{mol})$ and epibromohydrin $(2.9 \mu \mathrm{L}, 35 \mu \mathrm{mol})$ at room temperature. The mixture was 
heated to $75{ }^{\circ} \mathrm{C}$ and allowed to stir for $1.5 \mathrm{~h}$. After removing the solvent in vacuo, the residue was purified by flash column chromatography (silica, $\mathrm{CHCl}_{3}: \mathrm{MeOH}=20: 1$ ) to yield $\mathbf{1 b}(\mathrm{EP})$ as a dark purple solid (3.7 mg, 21\%). ${ }^{1} \mathrm{H}-\mathrm{NMR}\left(400 \mathrm{MHz}, \mathrm{CD}_{3} \mathrm{CN}\right): \delta 7.74-7.64(\mathrm{~m}$, 2H), 7.60-7.54 (m, 1H), 7.44-7.39 (m, 1H), 7.19 (d, 2H, $J=9.6 \mathrm{~Hz}), 7.12$ (d, 2H, $J=8.4 \mathrm{~Hz})$, $7.00(\mathrm{dd}, 2 \mathrm{H}, J=2.4,9.6 \mathrm{~Hz}), 6.99-6.80(\mathrm{~m}, 4 \mathrm{H}), 4.28(\mathrm{dd}, 1 \mathrm{H}, J=2.8,11.6 \mathrm{~Hz}), 3.77(\mathrm{dd}$, $1 \mathrm{H} J=6.0,11.2 \mathrm{~Hz}), 3.70-3.58(\mathrm{~m}, 8 \mathrm{H}), 3.34-3.20(\mathrm{~m}, 6 \mathrm{H}), 2.82(\mathrm{dd}, 1 \mathrm{H}, J=4.0,4.8 \mathrm{~Hz})$, $2.67(\mathrm{dd}, 1 \mathrm{H}, J=2.8,5.2 \mathrm{~Hz}), 2.26-1.98(\mathrm{~m}, 4 \mathrm{H}), 1.27(\mathrm{t}, 12 \mathrm{H}, J=7.2 \mathrm{~Hz}) .{ }^{13} \mathrm{C}-\mathrm{NMR}(100$ $\left.\mathrm{MHz}, \mathrm{CD}_{3} \mathrm{CN}\right): \delta 167.68,158.72,158.64,156.98,156.57,136.95,133.06,131.45,131.36$, $131.02,130.89,130.72,130.29,128.37,115.09,114.90,114.48,96.77,70.06,62.45,53.39$, 53.24, 50.72, 48.08, 46.58, 44.66, 42.25, 12.72. HRMS (ESI): Calcd for $\left(\mathrm{C}_{42} \mathrm{H}_{49} \mathrm{ClN}_{4} \mathrm{O}_{4}\right)^{+}$ 673.3748. Found: 673.3737.

\section{Synthesis of $1 \mathbf{c}(\mathrm{SF})$}

To a stirred solution of $\mathbf{1 - 2}(35 \mathrm{mg}, 55 \mu \mathrm{mol})$ in dry DMF $(3.5 \mathrm{~mL})$ was added 2-(1H-benzotriazol-1-yl)-1,1,3,3-tetramethyluronium hexafluorophosphate (HBTU) (27 mg, $72 \mu \mathrm{mol}), \mathrm{Et}_{3} \mathrm{~N}(70 \mu \mathrm{L}, 50 \mu \mathrm{mol})$ and 4-(2-aminoethyl)benzenesulfonyl fluoride hydrochloride (AEBSF-HCl) $(19 \mathrm{mg}, 80 \mu \mathrm{mol})$ at room temperature. The mixture was stirred for $2 \mathrm{~h}$. After removing the solvent in vacuo, the residue was purified by flash column chromatography (silica, $\mathrm{CHCl}_{3}: \mathrm{MeOH}=20: 1$ ) to yield $\mathbf{1 c}(\mathrm{SF})$ as a dark purple solid (10 mg, 22\%). ${ }^{1} \mathrm{H}-\mathrm{NMR}\left(400 \mathrm{MHz}, \mathrm{CD}_{3} \mathrm{CN}\right): \delta 8.02-7.90(\mathrm{~m}, 2 \mathrm{H}), 7.78-7.40(\mathrm{~m}, 6 \mathrm{H}), 7.20(\mathrm{~d}$, $2 \mathrm{H}, J=9.6 \mathrm{~Hz}), 6.97(\mathrm{dd}, 2 \mathrm{H}, J=2.8,9.6 \mathrm{~Hz}), 6.82(\mathrm{~d}, 2 \mathrm{H}, J=2.4), 3.73-3.54(\mathrm{~m}, 8 \mathrm{H})$, 3.50-3.18 (m, 10H), $2.89(\mathrm{t}, 2 \mathrm{H}, J=7.2), 2.47(\mathrm{t}, 2 \mathrm{H}, J=6.8 \mathrm{~Hz}), 2.30(\mathrm{t}, 2 \mathrm{H}, J=6.4 \mathrm{~Hz})$, $1.26(\mathrm{t}, 12 \mathrm{H}, J=7.2 \mathrm{~Hz}) .{ }^{13} \mathrm{C}-\mathrm{NMR}\left(100 \mathrm{MHz}, \mathrm{CD}_{3} \mathrm{CN}\right): \delta \quad 178.09,171.39,158.79,157.02$, $157.02,156.74,150.48,143.49,136.58,132.99,131.99,131.92,131.79,131.66,131.21$, $130.88,130.70,129.35,128.53,128.21,126.04,119.59,115.09,114.65,110.80,96.94,46.69$, 47.96, 46.69, 42.22, 40.53, 36.40, 31.45, 28.85HRMS (ESI): Calcd for $\left(\mathrm{C}_{44} \mathrm{H}_{51} \mathrm{FN}_{5} \mathrm{O}_{6} \mathrm{~S}\right)^{+}$ 796.3539. Found: 796.3527. 


\section{Synthesis of 1d(TE)}

To a stirred solution of 1-2 $(26 \mathrm{mg}, 40 \mu \mathrm{mol})$ in dry DMF $(3.0 \mathrm{~mL})$ was added thiophenol $(6.2$ $\mu \mathrm{L}, 60 \mu \mathrm{mol}$ ), 1-[bis(dimethylamino)methylene]-1H-1,2,3-triazolo[4,5-b]pyridinium 3-oxid hexafluorophosphate (HATU) $(22 \mathrm{mg}, 59 \mu \mathrm{mol})$ and $N, N$-diisopropylethylamine (DIEA) (14 $\mu \mathrm{L}, 80 \mu \mathrm{mol})$ at room temperature. The mixture was allowed to stir for $1 \mathrm{~h}$. After removing the solvent in vacuo, the residue was purified by flash column chromatography (silica, $\mathrm{CHCl}_{3}: \mathrm{MeOH}=20: 1$ to $\left.10: 1\right)$ to yield $\mathbf{1 d}(\mathrm{TE})$ as a dark purple solid (19 $\left.\mathrm{mg}, 64 \%\right)$. ${ }^{1} \mathrm{H}-\mathrm{NMR}\left(400 \mathrm{MHz}, \mathrm{CD}_{3} \mathrm{OD}\right): \delta 7.82-7.74(\mathrm{~m}, 2 \mathrm{H}), 7.74-7.68(\mathrm{~m}, 1 \mathrm{H}), 7.59-7.51(\mathrm{~m}, 1 \mathrm{H})$, $7.49-7.38(\mathrm{~m}, 5 \mathrm{H}), 7.26(\mathrm{~d}, 2 \mathrm{H}, J=9.6 \mathrm{~Hz}), 7.07(\mathrm{dd}, 2 \mathrm{H}, J=9.6,2.4 \mathrm{~Hz}), 6.95(\mathrm{~d}, 2 \mathrm{H}, J=$ $2.4 \mathrm{~Hz}), 3.66(\mathrm{q}, 8 \mathrm{H}, J=6.4 \mathrm{~Hz}), 3.54-3.36(\mathrm{~m}, 8 \mathrm{H}), 2.97(\mathrm{t}, 2 \mathrm{H}, J=7.2 \mathrm{~Hz}), 2.68(\mathrm{t}, 2 \mathrm{H}, J=$ $7.2 \mathrm{~Hz}), 1.29$ (t, $12 \mathrm{H}, J=7.2 \mathrm{~Hz}) .{ }^{13} \mathrm{C}-\mathrm{NMR}\left(100 \mathrm{MHz}, \mathrm{CD}_{3} \mathrm{CN}\right): \delta 197.80,170.32,168.14$, $158.78,157.03,156.72,136.58,135.63,132.98,131.93,130.87,130.69,130.45,130.26$, $128.98,128.51,115.08,114.63,96.93,47.91,46.68,42.35,39.12,28.712,12.80$. HRMS (ESI): Calcd for $\left(\mathrm{C}_{42} \mathrm{H}_{47} \mathrm{~N}_{4} \mathrm{O}_{4} \mathrm{~S}\right)^{+}$703.3313. Found: 703.3303 .

\section{Synthesis of 1e(TZ)}

To a stirred solution of 1-2 $(50 \mathrm{mg}, 77 \mu \mathrm{mol})$ in dry DMF $(1.5 \mathrm{~mL})$ was added 2-mercapto-2-thiazoline (14 mg, $0.12 \mathrm{mmol})$, EDCI-HCl (31 mg, $0.16 \mathrm{mmol})$ and DMAP (1.2 $\mathrm{mg}, 9.8 \mu \mathrm{mol})$ at room temperature. The mixture was allowed to stir for $4 \mathrm{~h}$. After removing the solvent in vacuo, the residue was dissolved in $\mathrm{CHCl}_{3}(30 \mathrm{~mL})$, and washed with $5 \%$ aqueous citric acid $(30 \mathrm{~mL})$ and brine $(30 \mathrm{~mL})$. The organic layer was dried over $\mathrm{Na}_{2} \mathrm{SO}_{4}$, filtered and evaporated. The crude was purified by flash column chromatography (silica, $\mathrm{CHCl}_{3}: \mathrm{MeOH}=10: 1$ to $\left.10: 3\right)$ to yield $1 \mathrm{e}(\mathrm{TZ})$ as a dark purple solid (41 $\mathrm{mg}, 70 \%$ ). ${ }^{1} \mathrm{H}-\mathrm{NMR}\left(400 \mathrm{MHz}, \mathrm{CD}_{3} \mathrm{OD}\right): \delta 7.77-7.63(\mathrm{~m}, 3 \mathrm{H}), 7.58-7.50(\mathrm{~m}, 1 \mathrm{H}), 7.44-7.30(\mathrm{~m}, 2 \mathrm{H})$, 6.88-6.82 (m, 2H), $6.70(\mathrm{~s}, 2 \mathrm{H}), 4.55(\mathrm{t}, 2 \mathrm{H}, J=7.6 \mathrm{~Hz}), 3.78-3.32(\mathrm{~m}, 16 \mathrm{H}), 3.30(\mathrm{t}, 2 \mathrm{H}, J=$ $7.2 \mathrm{~Hz}), 2.87$ (s, 2H), 2.73-2.56 (m, 2H), $1.34(\mathrm{~m}, 12 \mathrm{H}) .{ }^{13} \mathrm{C}-\mathrm{NMR}\left(100 \mathrm{MHz}, \mathrm{CD}_{3} \mathrm{CN}\right): \delta$ $203.92,174.89,170.87,168.13,158.74,156.98,156.70,136.57,132.97,131.89,131.18$, 
$130.85,130.67,128.51,115.10,114.61,96.92,57.37,47.93,46.68,42.33,29.32,28.59,12.80$. HRMS (ESI): Calcd for $\left(\mathrm{C}_{39} \mathrm{H}_{46} \mathrm{~N}_{5} \mathrm{O}_{4} \mathrm{~S}_{2}\right)^{+}$712.2986. Found: 712.2977.

\section{Synthesis of 1f(BP)}

To a stirred solution of 1-1 $(50 \mathrm{mg}, 91 \mu \mathrm{mol})$ in dry DMF $(1.2 \mathrm{~mL})$ was added p-benzoylbenzoic acid (31 mg, $0.14 \mathrm{mmol}), \quad$ EDCI-HCl $(32 \mathrm{mg}, 0.16 \mathrm{mmol})$, 1-hydroxybenzotriazole hydrate $\left(\mathrm{HOBt}-\mathrm{H}_{2} \mathrm{O}\right)(22 \mathrm{mg}, 0.14 \mathrm{mmol})$ and DIEA (157 $\mu \mathrm{L}, 0.275$ mmol) at room temperature. The mixture was allowed to stir for $2 \mathrm{~h}$. After removing the solvent in vacuo, the residue was dissolved in $\mathrm{CHCl}_{3}(30 \mathrm{~mL})$, and washed with $5 \%$ aqueous citric acid $(20 \mathrm{~mL} \times 3)$ and $1 \mathrm{M} \mathrm{NaHCO}_{3}(20 \mathrm{~mL})$. The organic layer was dried over $\mathrm{Na}_{2} \mathrm{SO}_{4}$, filtered and evaporated. The crude was purified by flash column chromatography (silica, $\mathrm{CHCl}_{3}: \mathrm{MeOH}=10: 1$ to $\left.10: 3\right)$ and RP-HPLC $\left(\mathrm{CH}_{3} \mathrm{CN}(0.1 \%\right.$ TFA $): \mathrm{H}_{2} \mathrm{O}(0.1 \%$ TFA $)=$ $30: 70(0 \mathrm{~min})>90: 10(40 \mathrm{~min})>30: 70(50 \mathrm{~min})$, detection; UV $(220 \mathrm{~nm}))$ to yield 1f(BP) as a dark purple solid (1.5 mg, 2\%). ${ }^{1} \mathrm{H}-\mathrm{NMR}\left(400 \mathrm{MHz}, \mathrm{CD}_{3} \mathrm{OD}\right): \delta 7.84-7.76(\mathrm{~m}$, 4H), 7.74-7.64 (m, 2H), 7.63-7.44 (m, 5H), 7.40-7.33 (m, 2H), $7.24(\mathrm{~m}, 2 \mathrm{H}), 7.00-6.71(\mathrm{~m}$, 2H), 3.79-3.19 (m, 16H), $1.33(\mathrm{t}, 12 \mathrm{H}, J=7.2 \mathrm{~Hz}) .{ }^{13} \mathrm{C}-\mathrm{NMR}\left(100 \mathrm{MHz}, \mathrm{CD}_{3} \mathrm{CN}\right): \delta$ $196.69,169.85,168.20,158.76,156.88,156.71,140.44,139.46,138.11,136.50,133.84$, $132.96,131.85,131.18,130.91,130.85,130.81,130.72,129.48,128.53,127.90,115.13$, 114.60, 96.95, 47.91, 46.70, 42.44, 12.83. HRMS (ESI): Calcd for $\left(\mathrm{C}_{46} \mathrm{H}_{47} \mathrm{~N}_{4} \mathrm{O}_{4}\right)^{+} 719.3592$. Found: 719.3579.

\section{Synthesis of $\lg (\mathrm{PA})$}

To a stirred solution of 1-1 (30 mg, $55 \mu \mathrm{mol})$ in dry DMF $(4.0 \mathrm{~mL})$ was added $\mathrm{HOBt}-\mathrm{H}_{2} \mathrm{O}(14$ mg, $93 \mu \mathrm{mol}), \mathrm{EDCI}-\mathrm{HCl}(19 \mathrm{mg}, 0.10 \mathrm{mmol}), \mathrm{Et}_{3} \mathrm{~N}(24 \mathrm{~mL}, 0.17 \mathrm{mmol})$ and 4-azidobenzoic acid $(15 \mathrm{mg}, 91 \mu \mathrm{mol})$ at room temperature. The mixture was allowed to stir for $8 \mathrm{~h}$. After removing the solvent in vacuo, the residue was purified by flash column chromatography (silica, $\mathrm{CHCl}_{3}: \mathrm{MeOH}=20: 1$ to $5: 1$ ) to yield $\mathbf{1 g}(\mathrm{PA})$ as a dark purple solid (29 $\mathrm{mg}, 73 \%$ ). 
${ }^{1} \mathrm{H}-\mathrm{NMR}\left(400 \mathrm{MHz}, \mathrm{CD}_{3} \mathrm{OD}\right): \delta 7.78-7.71(\mathrm{~m}, 3 \mathrm{H}), 7.72-7.39(\mathrm{~m}, 3 \mathrm{H}), 7.28(\mathrm{~d}, 2 \mathrm{H}, \mathrm{J}=8.8$ Hz), 7.15-7.05 (m, 4H), 6.97 (d, 2H, $J=2.4 \mathrm{~Hz}), 3.74-3.65$ (m, 8H), 3.51-3.34 (m, 8H), 1.31 (t, $12 \mathrm{H}, J=7.2 \mathrm{~Hz}) .{ }^{13} \mathrm{C}-\mathrm{NMR}\left(100 \mathrm{MHz}, \mathrm{CD}_{3} \mathrm{OD}\right): \delta 171.87,169.63,159.30,157.24$, $156.95,143.77,136.48,133.21,132.52,132.25,131.77,131.35,131.33,130.28,128.94$, 120.23, 115.45, 114.88, 97.36, 49.85, 46.91, 42.84, 12.84. HRMS (ESI): Calcd for $\left(\mathrm{C}_{39} \mathrm{H}_{42} \mathrm{~N}_{7} \mathrm{O}_{3}\right)^{+}$656.3344. Found: 656.3337 .

Synthesis of $\mathbf{1 h}(\mathrm{MI})$

To a stirred solution of 1-1 $(50 \mathrm{mg}, 91 \mu \mathrm{mol})$ in dry DMF $(1.5 \mathrm{~mL})$ was added 3-(maleimido)propionic acid $N$-hydroxysuccinimide ester (37 $\mathrm{mg}, 0.14 \mathrm{mmol}$ ) and DIEA (24 $\mu \mathrm{L}, 0.14 \mu \mathrm{mol})$ at room temperature. The mixture was allowed to stir for $12 \mathrm{~h}$, and added 3-(maleimido)propionic acid $N$-hydroxysuccinimide ester (25 mg, $94 \mu \mathrm{mol})$ and DIEA (24 $\mu \mathrm{L}$, $92 \mu \mathrm{mol})$. After stirring for $11 \mathrm{~h}$, the solvent was removed in vacuo, and the residue was purified by flash column chromatography (silica, $\mathrm{CHCl}_{3}: \mathrm{MeOH}=10: 1$ to $10: 3$ ) to yield $\mathbf{1 h}(\mathrm{MI})$ as a dark purple solid (55 mg, 86\%). ${ }^{1} \mathrm{H}-\mathrm{NMR}\left(400 \mathrm{MHz}, \mathrm{CD}_{3} \mathrm{OD}\right): \delta 7.82-7.73(\mathrm{~m}$, 2H), 7.72-7.66 (m, 1H), 7.56-7.48 (m, 1H), 7.28 (d, 2H, $J=9.6 \mathrm{~Hz}), 7.07$ (dd, 2H, $J=2.4$, $9.6 \mathrm{~Hz}), 6.96(\mathrm{~d}, 2 \mathrm{H}, J=2.4 \mathrm{~Hz}), 6.79(\mathrm{~s}, 2 \mathrm{H}), 3.78-3.61(\mathrm{~m}, 8 \mathrm{H}), 3.50-3.34(\mathrm{~m}, 8 \mathrm{H})$, 3.26-3.09 (m, 2H), $2.64(\mathrm{t}, 2 \mathrm{H}, J=7.2 \mathrm{~Hz}), 1.30(\mathrm{t}, 12 \mathrm{H}, J=6.8 \mathrm{~Hz}) .{ }^{13} \mathrm{C}-\mathrm{NMR}(100 \mathrm{MHz}$, $\left.\mathrm{CD}_{3} \mathrm{OD}\right): \delta 172.16,169.60,159.29,157.24,156.97,136.54,135.53,133.17,132.25$, $131.77,131.34,131.29,128.93,115.43,114.85,97.37,46.89,42.69,34.88,32.75$, 12.83.HRMS (ESI): Calcd for $\left(\mathrm{C}_{39} \mathrm{H}_{44} \mathrm{~N}_{5} \mathrm{O}_{5}\right)^{+}$662.3337. Found: 662.3328 . 


\section{References}

S1. Nguyen, T.; Francis, M. B. Org. Lett. 2003, 5, 3245.

S2. Kiefer, F.; Arnold, K.; Künzli, M.; Bordoli, L.; Schwede, T. Nucleic Acids Res. 2009, 37, 387.

S3. (a) Calvo, S. E.; Clauser, K. R.; Mootha, V. K. Nucleic Acids Res. 2015 [doi: 10.1093/nar/gkv1003]. (b) Pagliarini, D. J.; Calvo, S. E.; Chang, B.; Sheth, S. A; Vafai, S. B.; Ong, S.-E.; Walford, G. A; Sugiana, C.; Boneh, A.; Chen, W. K.; Hill, D. E.; Vidal, M.; Evans, J. G.; Thorburn, D. R.; Carr, S. A; Mootha, V. K. Cell 2008, 134, 112.

S4. Valencia-Cruz A.I., et al., PLoS ONE, 2013, 8: e54664.

S5. Molecular Probes Handbook: A Guide to Fluorescent Probes and Labeling Technologies, Johnson, I.; Spence, M. T. Z., Invitrogen, 11th ed, 2010

S6. Chen, Y.; Stevens, B.; Chang, J.; Milbrandt, J.; Barres, B. a.; Hell, J. W. J. Neurosci. Methods 2008, 171, 239.

S7. Yoshii, T.; Mizusawa, K.; Takaoka, Y.; Hamachi, I. J. Am. Chem. Soc. 2014, 136, 16635. 